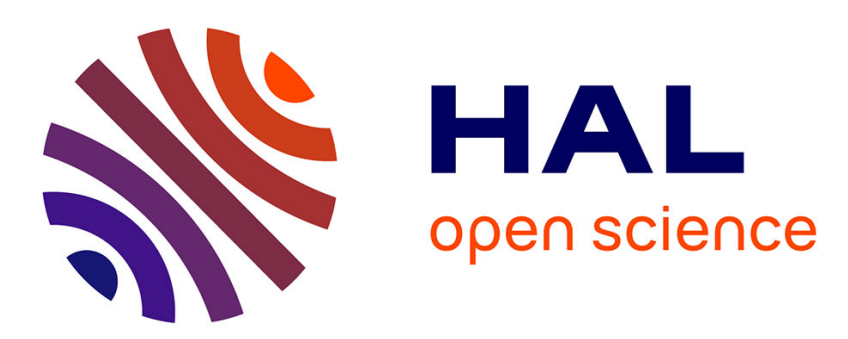

\title{
The Puzzling Conservation and Diversification of Lipid Droplets from Bacteria to Eukaryotes
}

\author{
Josselin Lupette, Eric Marechal
}

\section{To cite this version:}

Josselin Lupette, Eric Marechal. The Puzzling Conservation and Diversification of Lipid Droplets from Bacteria to Eukaryotes. Kloc M. Symbiosis: Cellular, Molecular, Medical and Evolutionary Aspects. Results and Problems in Cell Differentiation, 69, Springer, pp.281-334, 2020, 978-3-03051848-6. 10.1007/978-3-030-51849-3_11. hal-03048110

\section{HAL Id: hal-03048110 https://hal.science/hal-03048110}

Submitted on 9 Dec 2020

HAL is a multi-disciplinary open access archive for the deposit and dissemination of scientific research documents, whether they are published or not. The documents may come from teaching and research institutions in France or abroad, or from public or private research centers.
L'archive ouverte pluridisciplinaire HAL, est destinée au dépôt et à la diffusion de documents scientifiques de niveau recherche, publiés ou non, émanant des établissements d'enseignement et de recherche français ou étrangers, des laboratoires publics ou privés. 


\title{
Chapter 11 \\ The Puzzling Conservation \\ and Diversification of Lipid Droplets from Bacteria to Eukaryotes
}

\begin{abstract}
Membrane compartments are amongst the most fascinating markers of 6 cell evolution from prokaryotes to eukaryotes, some being conserved and the others 7 having emerged via a series of primary and secondary endosymbiosis events. 8 Membrane compartments comprise the system limiting cells (one or two membranes 9 in bacteria, a unique plasma membrane in eukaryotes) and a variety of internal 10 vesicular, subspherical, tubular, or reticulated organelles. In eukaryotes, the internal 11 membranes comprise on the one hand the general endomembrane system, a dynamic 12 network including organelles like the endoplasmic reticulum, the Golgi apparatus, 13 the nuclear envelope, etc. and also the plasma membrane, which are linked via direct 14 lateral connectivity (e.g. between the endoplasmic reticulum and the nuclear outer 15 envelope membrane) or indirectly via vesicular trafficking. On the other hand, semi- 16 autonomous organelles, i.e. mitochondria and chloroplasts, are disconnected from 17 the endomembrane system and request vertical transmission following cell division. 18 Membranes are organized as lipid bilayers in which proteins are embedded. The 19 budding of some of these membranes, leading to the formation of the so-called lipid 20 droplets (LDs) loaded with hydrophobic molecules, most notably triacylglycerol, is 21 conserved in all clades. The evolution of eukaryotes is marked by the acquisition of 22 mitochondria and simple plastids from Gram-positive bacteria by primary endosym- 23 biosis events and the emergence of extremely complex plastids, collectively called 24 secondary plastids, bounded by three to four membranes, following multiple and 25 independent secondary endosymbiosis events. There is currently no consensus view 26 of the evolution of LDs in the Tree of Life. Some features are conserved; others show 27
\end{abstract}

Josselin Lupette and Eric Maréchal contributed equally with all other contributors.

J. Lupette $(\triangle)$

MSU-DOE Plant Research Laboratory, Michigan State University, East Lansing, MI, USA

e-mail: lupettej@msu.edu

E. Maréchal (ه)

Laboratoire de Physiologie Cellulaire et Végétale, CNRS, CEA, INRA, Université Grenoble

Alpes, Institut de Recherche Interdisciplinaire de Grenoble, Grenoble, France

e-mail: eric.marechal@cea.fr 


\subsection{Introduction} encountered.

a striking level of diversification. Here, we summarize the current knowledge on the architecture, dynamics, and multitude of functions of the lipid droplets in prokaryotes and in eukaryotes deriving from primary and secondary endosymbiosis events.

Keywords Lipid droplets · Evolution · Architecture $\cdot$ Biogenesis · Catabolism

Lipid droplets (LDs) are conserved structures in prokaryotic and eukaryotic cells (Walther et al. 2017; Zhang and Liu 2017). Their architecture consists of a core, loaded with hydrophobic carbon-rich molecules (polyhydroxyalkanoates or PHAs, triacylglycerol or TAG, steryl esters, isoprenoids such as squalene, etc.) bounded by a monolayer of polar glycerolipids, generally phospholipids that can be associated with sterols. Proteins are transiently or permanently associated with its surface (Walther et al. 2017) (Fig. 11.1). Two main classes have been identified amongst LD closely associated proteins, based on their structure (Kory et al. 2016). Class I proteins have a hydrophobic "hairpin" pattern (Bersuker and Olzmann 2017) and class II proteins have at least one amphipathic helix (Bersuker and Olzmann 2017) (Fig. 11.1). Nevertheless, proteins that do not belong to these two classes are also

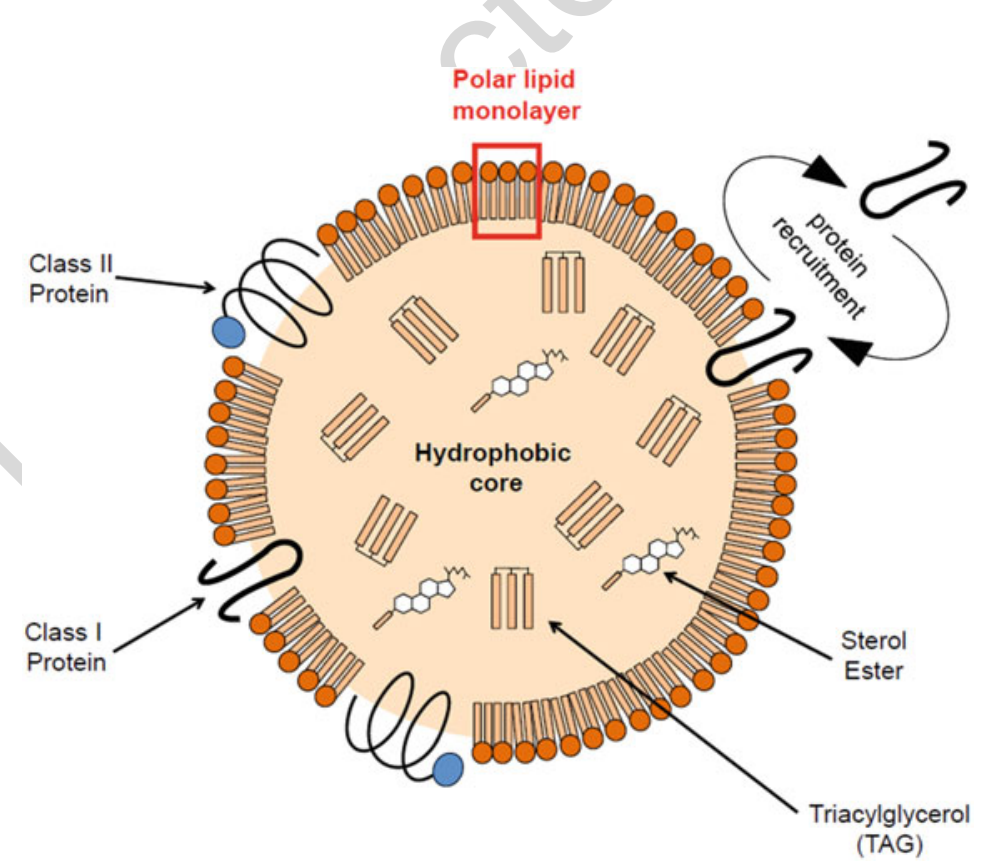

Fig. 11.1 General architecture of a triacylglycerol-containing lipid droplet 
LDs derive from the budding of a cell membrane. Membrane compartments are 45 amongst the most fascinating markers of cell evolution from prokaryotes to eukary- 46 otes, some being conserved and the others having emerged via a series of primary 47 and secondary endosymbiosis events. Membrane compartments comprise the system 48 limiting cells (one or two membranes in bacteria, a unique plasma membrane in 49 eukaryotes) and a variety of internal vesicular, subspherical, tubular, or reticulated 50 organelles. In eukaryotes, the internal membranes comprise on the one hand 51 the general endomembrane system, a dynamic network including organelles like 52 the endoplasmic reticulum (ER), the Golgi apparatus, nuclear envelope, etc. and also 53 the plasma membrane, which are linked via direct lateral connectivity (e.g. between 54 the endoplasmic reticulum and the nuclear outer envelope membrane) or indirectly 55 via vesicular trafficking. On the other hand, semi-autonomous organelles, 56 i.e. mitochondria and chloroplasts, are disconnected from the endomembrane system 57 and request vertical transmission following cell division. Membranes are organized 58 as lipid bilayers in which proteins are embedded. The evolution of eukaryotes is 59 marked by the acquisition of mitochondria and simple plastids from Gram-negative 60 bacteria by primary endosymbiosis events (Maréchal 2018), and the emergence of 61 extremely complex plastids, collectively called secondary plastids, bounded by three 62 to four membranes, following multiple and independent secondary endosymbiosis 63 events (Fussy 2018). There is currently no consensus view on the evolution of cell 64 membranes and that of LDs.

Due to their hydrophobic core loaded with carbon-rich molecules, LDs have long 66 been considered as simple carbon and energy storage organelles. Based on the 67 analyses of LD proteomes in various cell models, it is now considered that LDs 68 have other functions that depend on their protein composition (Walther et al. 2017; 69 Den Brok et al. 2018; Henne et al. 2018).

Research on LDs has increased strikingly in recent decades motivated by the 71 multitude of applications ranging from nutrition, health to green chemistry and 72 bioenergy. In 2020, the keyword "lipid droplet" returns as many as 12,500 hits in 73 the Pubmed bibliographic database. Concerning human obesity-related diseases 74 (Faucher and Poitou 2016; Madrigal-Matute and Cuervo 2016), protein actors 75 (CGI-58, SEIPIN, ATGL, LAL) at the surface of LDs have been extensively studied 76 in mammalian models (summarized in Table 11.1). CGI-58-ABHD5 (Comparative 77 Gene Identification $58-\alpha / \beta$ hydrolase domain-containing $5 ; 349$ amino acids -78 $45 \mathrm{kDa}$ ) is particularly studied because its mutation is responsible for the 79 Chanarin-Dorfman syndrome, an autosomal recessive disease (Missaglia et al. 80 2014). In mammals, the CGI-58 protein is located on cytosolic LDs interacting 81 with PLIN1 (Subramanian et al. 2004). A second important player in the mecha- 82 nisms of LD biogenesis in mammals is the SEIPIN protein. A mutation in the human 83 Seipin gene leads to severe forms of generalized Berardinelli-Seip congenital 84 lipodystrophy (Magré et al. 2001). The deletion of ATGL (Adipose triglyceride 85 lipase) in mice reduces the mechanism of lipolysis and promotes the accumulation of 86 lipids in oxidative tissues of the body, leading to the death of mice in 3 months 87 (Zimmermann et al. 2004). The last example is the Wolman disease, which is an 88 autosomal recessive disease affecting young children following a mutation in the 89 
t1.1 Table 11.1 Human diseases related to LD formation

\begin{tabular}{|c|c|c|c|}
\hline Diseases & Anatomical pathology & Pathophysiology & References \\
\hline Atherosclerosis & $\begin{array}{l}\text { Accumulation of atheroma- } \\
\text { tous plaques (cholesterol) in } \\
\text { the arteries }\end{array}$ & $\begin{array}{l}\text { ACAT1; } \\
\text { ABCA1; ADRP }\end{array}$ & Paul et al. (2008) \\
\hline Obesity & $\begin{array}{l}\text { Accumulation of fat } \\
\text { reserves }\end{array}$ & $\begin{array}{l}\text { Multifactorial } \\
\text { (genetic, envi- } \\
\text { ronmental, } \\
\text { psychological) }\end{array}$ & Faucher and Poitou (2016) \\
\hline Fatty liver & $\begin{array}{l}\text { Accumulation of TAGs in } \\
\text { the cytoplasm of } \\
\text { hepatocytes }\end{array}$ & $\begin{array}{l}\text { Alcohol, hepati- } \\
\text { tis B and C }\end{array}$ & $\begin{array}{l}\text { Madrigal-Matute and } \\
\text { Cuervo (2016) }\end{array}$ \\
\hline $\begin{array}{l}\text { Chanarin- } \\
\text { Dorfman } \\
\text { syndrome }\end{array}$ & $\begin{array}{l}\text { Accumulation of lipid } \\
\text { droplets in lymphocytes and } \\
\text { many tissues }\end{array}$ & $\begin{array}{l}\text { Mutation of } \\
\text { CGI-58/ABHD5 }\end{array}$ & $\begin{array}{l}\text { Dorfman et al. (1974), } \\
\text { Chanarin et al. (1975), } \\
\text { Lefèvre et al. (2001), } \\
\text { Samuelov et al. (2011), } \\
\text { Missaglia et al. (2014), } \\
\text { Jordans (1953), Gupta and } \\
\text { Kaur (2005), Waheed et al. } \\
\text { (2016) }\end{array}$ \\
\hline Myopathy & & $\begin{array}{l}\text { Mutation of } \\
\text { PNPLA2 }\end{array}$ & Zimmermann et al. (2004) \\
\hline $\begin{array}{l}\text { Congenital } \\
\text { generalized } \\
\text { Lipodystrophy } \\
\text { (CGL) }\end{array}$ & Dystrophy of adipose tissue & $\begin{array}{l}\text { Mutation of } \\
\text { AGPAT2, } \\
\text { BSCL2, CAV1 } \\
\text { or PTRF }\end{array}$ & $\begin{array}{l}\text { Magré et al. (2001), } \\
\text { Agarwal et al. (2002), Kim } \\
\text { et al. (2008), Hayashi et al. } \\
\text { (2009), Rajab et al. (2010), } \\
\text { Quinn and Purcell (2017) }\end{array}$ \\
\hline $\begin{array}{l}\text { Lysosomal } \\
\text { acid lipase } \\
\text { deficiency }\end{array}$ & $\begin{array}{l}\text { Lysosomal acid lipase defi- } \\
\text { ciency causing an accumu- } \\
\text { lation of TAGs and } \\
\text { cholesterol esters in leuko- } \\
\text { cytes, hepatocytes, and } \\
\text { fibroblasts }\end{array}$ & $\begin{array}{l}\text { Mutation of } \\
\text { LIPA }\end{array}$ & $\begin{array}{l}\text { Wolman et al. (1961), Onal } \\
\text { et al. (2017), Pericleous } \\
\text { et al. (2017), Ikari et al. } \\
\text { (2018) }\end{array}$ \\
\hline
\end{tabular}

LIPA gene (Wolman et al. 1961). The LIPA mutation leads to the synthesis deficiency of lysosomal acid lipase (LAL) (Onal et al. 2017). This disease causes accumulation of cholesterol esters and TAG in leukocyte lysosomes, fibroblasts, and hepatocytes generally leading to the death of the child by liver failure (Pericleous et al. 2017). It is a very rare disease with only 14 cases detected so far, half of which are from the consanguineous union (Ikari et al. 2018).

TAG-rich LDs produced by oleaginous organisms, mainly plants and algae, but sometimes also fungi or animals, are also key to numerous biotechnological applications. Molecules of TAG are composed of a glycerol-3-phosphate backbone on which three fatty acids are esterified (Lupette and Maréchal 2018). Fatty acids (FAs) are carboxylic acids. Their carbon chain length and number of unsaturations (or double bonds, $\mathrm{C}=\mathrm{C}$ ) allow assessing whether they can be used for different applications. Oleaginous crops are an essential resource for human nutrition. Microalgae, whose interest in the scientific community is currently exponential, 
can also produce TAGs. Microalgae enriched in FAs with short or medium carbon 104 chains without unsaturation are an interesting feedstock for green chemistry or the 105 development of biofuels (Lupette and Maréchal 2018). Microalgae containing high 106 levels of very long-chain fatty acids (carbon number greater than 20) with multiple 107 unsaturations (1-6), called VLC-PUFAs, with unsaturation at the $\omega$-3 position 108 (i.e. eicosapentaenoic acid or EPA, 20:5, and docosahexaenoic acid or DHA, 109 22:6), are promising for human health applications (Lupette and Maréchal 2018). 110

There is currently no consensus view of the evolution of LDs in the Tree of Life. 111 Some features are conserved; others show a striking level of diversification. Here, we 112 summarize the current knowledge on the architecture, dynamics, and multitude of 113 functions of the lipid droplets in prokaryotes and eukaryotes deriving from primary 114 and secondary endosymbiosis events.

\subsection{Studying Lipid Droplets}

\subsubsection{Imaging Lipid Droplets}

Microscopic observation by confocal or epifluorescence imaging is the main method 118 of detection of LDs in a cell or an organelle. The most commonly used fluorophores 119 are Nile Red (Greenspan et al. 1985) and BODIPY 505/515 (Rumin et al. 2015) or 120 BODIPY 493/503 (Gocze and Freeman 1994). More recently, new fluorophores 121 have been developed (Yang et al. 2012; Gidda et al. 2016). These molecules are 122 compatible with the parallel measurement of the fluorescence of GFP (Green 123 Fluorescent Protein), RFP (Red Fluorescent Protein), and of chlorophyll (Kuntam 124 et al. 2015). Other compounds including AC-202 were recently used in two model 125 species of microalgae Chlamydomonas reinhardtii and Phaeodactylum tricornutum 126 (Harchouni et al. 2018). These fluorophores make it possible to determine the size 127 and number of LDs in a semi-quantitative manner, as well as their cellular 128 localization.

\subsubsection{Purifying Lipid Droplets}

The general strategy for studying LD architecture is similar regardless of the 131 organism studied. A culture of cells in a medium promoting the development of 132 LDs is used (e.g. a nutrient deficiency). The LD purification starts by a gentle cell 133 disruption step (French press, cell disruptor, etc.) in a suitable buffer releasing 134 droplets as well as other cellular components. It is then necessary to perform a 135 density gradient purification (Brasaemle and Wolins 2016). Due to their low density, 136 LDs rise to the surface of the gradient during ultracentrifugation (Brasaemle and 137 Wolins 2016). LDs are harvested and washed to limit the presence of contaminants. 138 The study of LD architecture is based first on the determination of all the 139 
components of the hydrophobic core and on the composition of the monolayer of polar lipids and proteins on the surface of the droplet (Walther et al. 2017). Proteomic analyses allow the identification of proteins but also the characterization of some post-translational modifications (phosphorylation, nitrosylation, ubiquitinylation, sumoylation, $N$ and $O$-glycosylation, farnesylation). The proteome must then be validated by biochemical studies (western blot), the imaging of fusion proteins (with a fluorescent marker to verify the location on the surface of LDs), and functional genetic studies (the study of mutants with altered expression such as knockout, silencing, and overexpression of genes coding for droplet proteins allows their functional characterization).

\subsubsection{Biophysical Properties of Lipid Droplets}

Biophysical studies of LDs have proven to be critical to advance our understanding of LD biogenesis. After the removal of proteins and polar lipids, it is possible to consider LDs as the product of an emulsion of oil in water (Thiam et al. 2013b). The cytosol of the cell represents the aqueous phase and LDs, the dispersed oily phase. The interface between oil and water generates a surface tension due to the lack of cohesive integrations between the two phases. These emulsions are metastable in the absence of external disturbance. The presence of surfactants makes it possible to reduce the surface tension, thus increasing the (meta)stability of the emulsion and the cohesion energy cost (Georgieva et al. 2009). The polar glycerolipids at the periphery of the droplet then act as surfactants. Mastering this system in vitro is probably one of the most important challenges to understand how such anisotropic hydrophobic cores can be maintained in a cell, where all other components are highly selfassembled and organized (membranes can be considered as two-dimensional fluid crystals, DNA and polymers have three-dimensional architectures, polypeptides form protein structures with rigorous three-dimensional folds). It is also possible to use biophysical methods such as Pulsed Field Gradient-Nuclear Magnetic Resonance (PFG-NMR) to determine the mobility of TAGs inside the volume set by LDs with or without LD-to-LD connections (Gromova et al. 2015). Since the overall structure of LDs appears conserved in the Tree of Life, whereas components may differ, a key to LD conservation may rely on biophysical properties, which now need to be evaluated in different systems.

\subsection{Lipid Droplets in the Tree of Life}

\subsubsection{Lipid Droplets in Prokaryotic Cells}

The vast majority of bacterial species have the capacity to accumulate lipid compounds within their cytoplasm, especially during nutritional stress. A distinction is 
made according to accumulated hydrophobic molecules, with either "lipid droplets" 176 (containing fluid acyl esters, triacylglycerols, or TAGs) or "granules" (containing 177 semi-solid lipopolymers called polyhydroxyalkanoates or PHAs). Here, we describe 178 the formation of LD structures in bacteria, as a possible basis for their evolution in 179 eukaryotes following primary endosymbiosis events. Since primary endosymbiosis 180 events are believed to be facilitated by the presence of pathogenic partners (Maréchal 181 2018), we also describe how some pathogenic bacteria (and viruses) are known to 182 interact with host cell LDs.

\subsubsection{Polyhydroxyalkanoate Granules}

Polyhydroxyalkanoates (PHAs) are polyesters produced by fermentation of lipids or 185 carbohydrates. They are linear polyesters consisting of hydroxy acid monomers 186 (HA) linked together by an ester bond (Możejko-Ciesielska and Kiewisz 2016). 187 PHAs include poly(3-hydroxybutyrate) (PHB) and polyhydroxyvalerate (PHV) 188 (Murphy 2012). PHAs are also classified into two groups according to the number 189 of carbons per monomer: short-chain (3-5 carbons) PHAs and medium-chain PHAs 190 (6-14 carbons). PHAs are synthesized when the $\mathrm{C} / \mathrm{N}$ ratio is altered (a nitrogen 191 deficiency coupled with an excess of carbon), stopping growth and division, 192 resulting in an entry into the quiescent phase. Special attention has been given to 193 these polyesters for several decades because they are biodegradable (Pötter and 194 Steinbüchel 2006). PHAs are used in a wide range of applications such as resorbable 195 materials for medical purposes (implants, biodegradable sutures, stents, etc.), mate- 196 rials (paper coating, shape memory gel, etc.), fuel additives, and as metabolic 197 regulators (Możejko-Ciesielska and Kiewisz 2016). 198

Ralstonia eutropha H16 (new name: Cupriavidus necator) is the study model for 199 PHB granules (Reinecke and Steinbüchel 2009). It is a Gram-negative bacterium 200 that can accumulate 10-20 granules per cell, measuring $500 \mathrm{~nm}$ in diameter and 201 representing $90 \%$ of the dry weight (Anderson and Dawes 1990). A recent study has 202 shown that R.eutropha H16 PHB granules do not have a monolayer of polar lipids 203 but only superficial proteins essential for their synthesis and degradation (Bresan 204 et al. 2016). The main proteins detected on their surface are PHB synthase (PhaC), 205 phasin (PhaP), PhaR (PhaR), and PHB depolymerase (PhaZ). The R. eutropha H16 206 PhaC gene has been cloned by three independent laboratories. The localization of the 207 PHB synthase on the surface of the granules was confirmed by immunocytochemical 208 staining with colloidal gold (Gerngross et al. 1993). The study of PHA granules is 209 still too scarce to assess whether they are linked to TAG containing LDs and whether 210 they may also be present in some eukaryotic clades.

\subsubsection{TAG and Wax Ester Droplets}

Bacteria are also able to accumulate TAG in LDs. Bacterial species producing LDs 213 have been described in the following genera: Mycobacterium, Nocardia, 214 
Rhodococcus, Micromonospora, Dietzia, and Gordonia as well as several Streptomycetes (Alvarez and Steinbüchel 2002; Wältermann and Steinbüchel 2005; Murphy 2012). $\gamma$-Proteobacteria (Marinobacter, Alcanivorax, etc.) are hydrocarbonbased bacteria capable of accumulating LDs (TAGs and wax esters) when entering dormancy (Kalscheuer et al. 2007). These $\gamma$-proteobacteria are often found in the oceans associated with microalgae in a system called the phycosphere (Lupette et al. 2016). These bacteria are also able to use petroleum hydrocarbons as a source of carbon raising possible applications in the degradation of hydrocarbons during oil spills (Murphy 2012).

Rhodococcus are oleaginous bacteria containing large amounts of TAGs (Alvarez 2016). Proteomic studies of LDs of several Rhodococcus species have been performed: Rhodococcus opacus and Rhodococcus ruber (Kalscheuer et al. 2001), Rhodococcus jostii RHA1 (Ding et al. 2012b), and Rhodococcus opacus PD630 (Kalscheuer et al. 2001; Chen et al. 2014). 228 proteins have been identified in $R$. jostii RHA1 including two putative structural proteins representing $15 \%$ of LD proteins: Microorganism Lipid Droplet Small (MLDS) and Phage shock protein A (Psp A). Ribosomes and translational regulators have also been isolated in the proteome of the LD of $R$. jostii RHA1 (Ding et al. 2012b). By a functional genetic study, deletion of the MLDS causes the formation of larger LDs (Ding et al. 2012b). A recent study showed that LDs of $R$. jostii RHA1 are bound to genomic DNA via MLDS protein, which increases the survival rate of bacterial cells during nutritional deficiency or genotoxic stress (Zhang et al. 2017).

\subsubsection{Pathogenic Bacteria}

Pathogenic bacteria can divert lipids and even 'hijack' LDs from an infected host. Well-known examples include bacteria of the genera Mycobacterium and Chlamydia. Mycobacteria are bacilli with pathogenic potency: Mycobacterium tuberculosis (Menon et al. 2019), M. bovis, and M. avium are causative agents of tuberculosis, M. leprae is the agent of leprosy, and M. ulcerans is responsible for Buruli ulcer. Mycobacteria are able to disrupt human lipid homeostasis during infection following the formation of foamy macrophages containing LDs in the cytoplasm (Kim et al. 2010; Caire-Brändli et al. 2014). LDs produced in infected cells serve as a platform for the production of signaling molecules (prostaglandins and leukotrienes eicosanoids) regulating the immune response and inflammation (Melo and Weller 2016). LDs also serve to concentrate and deliver iron via lipophilic siderophores (mycobactins) secreted by the bacteria (Luo et al. 2005). The LD proteome of Bacillus Calmette and Guerin (BCG: a non-replicating hypoxic attenuated strain of $M$. bovis) used in the tuberculosis vaccine allowed the identification of five proteins: two triacylglycerol synthases, Tgs1 (BCG3153c) and Tgs2 (BCG3794c), as well as three other proteins, BCG1169c, BCG1489c, and BCG1721 (Low et al. 2010). BCG1169c is a specific protein of the Mycobacterium clade. BCG1489c codes for a putative AGPAT involved in the formation of PA in 
the Kennedy pathway. A deletion of BCG1489C causes a decrease in the amount 256 of TAG.

Chlamydia trachomatis is an obligate intracellular bacterium responsible for 258 sexually transmitted infections as well as eye diseases. This bacterium has a biphasic 259 life cycle: the elementary body representing the infectious form and the 260 non-infectious reticulate body. $C$. trachomatis is able to translocate an LD from 261 the cytoplasm of the host to the parasitophorous vacuole lumen containing the 262 bacterium via an endocytosis process. Internalization occurs after LDs are coated 263 with a family of Lda proteins (Kumar et al. 2006). The proteome of LDs of HeLa 264 human cervical adenocarcinoma epithelial cells infected with C. trachomatis 265 LGV-L2 434/Bu showed that they are enriched in PLIN2, PLIN3, ACSL-3, and 266 ACSL-4 proteins (Saka et al. 2015).

\subsubsection{Hijacking of Lipid Droplets by Viruses}

LDs can serve as a source of energy for the dispersion of viruses such as hepatitis C 269 virus (HCV), dengue virus (DENV), poliovirus (PV), or rotavirus (RV). This section 270 presents several examples of 'hijacking' of lipid metabolism by viruses.

$\mathrm{HCV}$ is the most widely used model for studying LD diversion (Roingeard and 272 Melo 2017). The virion initially circulates in a form of lipoviroparticles (rich in 273 cholesterol esters and apolipoproteins apoB and apoE) in the blood of infected 274 patients (Boyer et al. 2014). Its entry into the cell is dependent on LDL receptors 275 (Low Density Lipoproteins). The replication of the viral RNA then induces exten- 276 sive alterations of the membrane and the formation of vesicular structures that 277 exhibit features similar to lipid rafts (Aizaki et al. 2004). The assembly of HCV 278 requires the localization of some of the HCV proteins in LDs of the host, and the 279 release of virions is strongly associated with the secretion pathway of very 280 low-density lipoproteins (VLDL). Proteins that are important to complete the viral 281 cycle, i.e. the nucleocapsid of HCV and the nonstructural protein NS5A co-localize 282 with the LD in HCV-infected cells and interact with LD proteins, such as DGAT1 283 (Camus et al. 2013). 284

Other examples of viruses depending on host cell LDs to complete their cycle 285 include DENV in mosquitoes (Mayer et al. 2017), PV causing poliomyelitis 286 (Nchoutmboube et al. 2013), Flock House Virus (Castorena et al. 2010), Brome 287 mosaic virus (BMV) (Zhang et al. 2016), or RV causing gastroenteritis in infants and 288 young children (Gaunt et al. 2013).

\subsubsection{Lipid Droplets in Eukaryotic Cells}

Eukaryotes including unicellular and multicellular organisms are characterized by 291 the presence of membrane organelles (endoplasmic reticulum, nucleus, Golgi, 292 
trans-Golgi network, peroxisomes, lysosomes, vacuoles, and numerous cytosolic vesicles for the endomembrane system, mitochondria, and chloroplast for semi-autonomous organelles). Primary endosymbiosis events are at the origin of mitochondria and primary plastids. In a very simplistic scheme, mitochondria are considered to derive from Gram-negative alpha-proteobacteria and primary plastids, from Gram-negative cyanobacteria. Based on molecular evidence, other partners have been involved, including pathogenic bacteria (Maréchal 2018). In contrast to prokaryotes, the synthesis of LDs from the ER seems to occur nearly in all eukaryotes studied to date.

In this section, we first consider non-photosynthetic eukaryotes, containing mitochondria as unique semi-autonomous organelles, then photosynthetic eukaryotes containing primary plastids, and finally those containing secondary plastids.

\subsubsection{Opisthokonta: Non-photosynthetic Eukaryotes}

\section{Metazoa}

\section{Chordata}

LDs of mammals are composed of a hydrophobic core consisting of TAGs and cholesteryl esters, generally considered as a form of storage. The monolayer of polar lipids is mainly composed of PC, PE, and PI (Bartz et al. 2007). In mammals, LD surface proteins are grouped into a family formerly called PAT (for PerilipinAdipophilin-Tail-interacting protein of $47 \mathrm{kDa}$ ) (Bickel et al. 2009) but whose nomenclature has evolved since 2010 under the name of Perilipin (PLIN) (Kimmel et al. 2010). PLIN1 has four splice variants PLIN1a, PLIN1b, PLIN1c, and PLIN1d (Kimmel et al. 2010). PLINs contain a hydrophobic PAT domain of 100 amino acids defining an N-terminal region. The study of a mutant PLIN2-N1 (deficient for the PAT domain) reveals that this domain is not involved in lipid binding, but in the stabilization of lipid droplets, and lipid accumulation and degradation of PLIN2 by the proteasome (Najt et al. 2014). The PAT domain is followed by an 11-mer helical pattern of variable size, which might interact with phospholipids (Bussell and Eliezer 2003). Some PLIN proteins can be post-translationally modified by phosphorylations, via PKA, during lipolysis (PLIN3 and PLIN4 do not have a phosphorylation site (Kimmel and Sztalryd 2016)). Recently, the sixth clade of Perilipin, called PLIN6, has been discovered, specific to teleosts (Granneman et al. 2017). Interestingly, PLIN6 is not expressed in tissues associated with lipid metabolism but in the xanthophores of teleost skin. Biochemical analyses have shown that PLIN6 is associated with the surface of droplets enriched in carotenoids and regulates the pigment synthesis pathways (Granneman et al. 2017).

The expression of PLINs (with the exception of PLIN3) is regulated by a family of transcription factors called PPAR (Peroxisome Proliferator Activated Receptor). These transcription factors are activated by the binding of lipid ligands (Poulsen et al. 2012). 
Since the early 2000s, at least 25 proteomic studies of the LD of mammalian cells 333 or tissues have been published (Table 11.2). In all these studies, proteomics reveals 334 the presence of at least one of the classes of PLIN on the surface of the mammalian 335 LD. It can also be seen that the distribution of the PLINs varies according to 336 mammalian cells and tissues. PLIN1 and PLIN4 are present on the surface of LDs 337 of adipocytes (Ding et al. 2012a) and adipose tissue (Yu et al. 2015). PLIN2 and 338 PLIN3 are ubiquitous in non-adipose tissues. PLIN2 is strongly expressed on the 339 surface of LDs of the liver and hepatocytes. PLIN5 is present in the oxidative tissues 340 i.e. the heart, brown adipose tissue, and skeletal muscles (Kimmel and Sztalryd 341 2014).

Functional studies of PLIN have been performed upstream and downstream of 343 proteomic studies. KO mice for PLIN1 have a phenotype of reduction of fat mass, an 344 increase of the lipolytic activity, but also a glucose intolerance and peripheral insulin 345 resistance (Tansey et al. 2001). Stimulation of lipolytic activity by tumor necrosis 346 factor (TNF- $\alpha$ ) showed, in a first study, a decrease in the expression of PLIN1 347 variants. However, the overexpression of PLIN1a and PLIN1b blocks the ability of 348 TNF- $\alpha$ to increase lipolysis in 3T3-L1 cells (Souza et al. 1998). KO mice for PLIN2 349 present unchanged adipose differentiation, a $60 \%$ decrease in hepatic TAGs, but a 350 level of VLDL identical to control mice suggesting the retention of TAGs in the 351 microsomes (Chang et al. 2006). Overexpression of PLIN2 fused to GFP causes an 352 increase in the number and size of LDs in hepatocytes (Imamura et al. 2002). A first 353 antisense study of hepatic PLIN2 causes a decrease in hepatic steatosis, 354 hypertriglyceridemia, and insulin resistance in obese mice without altering the 355 level of expression of PLIN3 and PLIN4 (Imai et al. 2007). A second antisense 356 study of PLIN2 shows the same type of result with a decrease in DAG and TAG in 357 the liver as well as an improvement in insulin production (Varela et al. 2008). 358 Finally, deletion of the PLIN2 exon $5(\operatorname{Plin} 2 \Delta 5)$ in mice causes resistance to obesity 359 induced by a diet rich in fats indicating the role of PLIN2 in obesity and hepatic 360 steatosis (Mcmanaman et al. 2013). The deletion of PLIN3 in mice induces cold 361 tolerance (Lee et al. 2018), probably by regulating beige adipocyte formation and 362 thermogenic activities. The deletion of PLIN4 leads to decreased expression of 363 PLIN5 reducing lipid accumulation in the cardiac muscle (Chen et al. 2013). KO 364 of PLIN6 is responsible for stopping the concentration of carotenoids in the droplets 365 (Granneman et al. 2017).

\section{Arthropoda}

Research on LDs of Arthropoda was mainly carried out in the fruit fly Drosophila 368 melanogaster. LD research began with two RNAi screens (Beller et al. 2008; Guo 369 et al. 2008) showing that approximately 370 genes, or $1.5 \%$ of the expressed 370 genome, were involved in LD physiology. A first proteomic study was conducted 371 on the abdominal fat body, the fat tissue of the fly, which allowed the identification 372 of 248 proteins (Beller et al. 2006). A second study was conducted on whole 373 embryos (Cermelli et al. 2006). The proteomes of the LD of D. melanogaster have 374 similarities with those of mammals. There are, for example, two members of the 375 


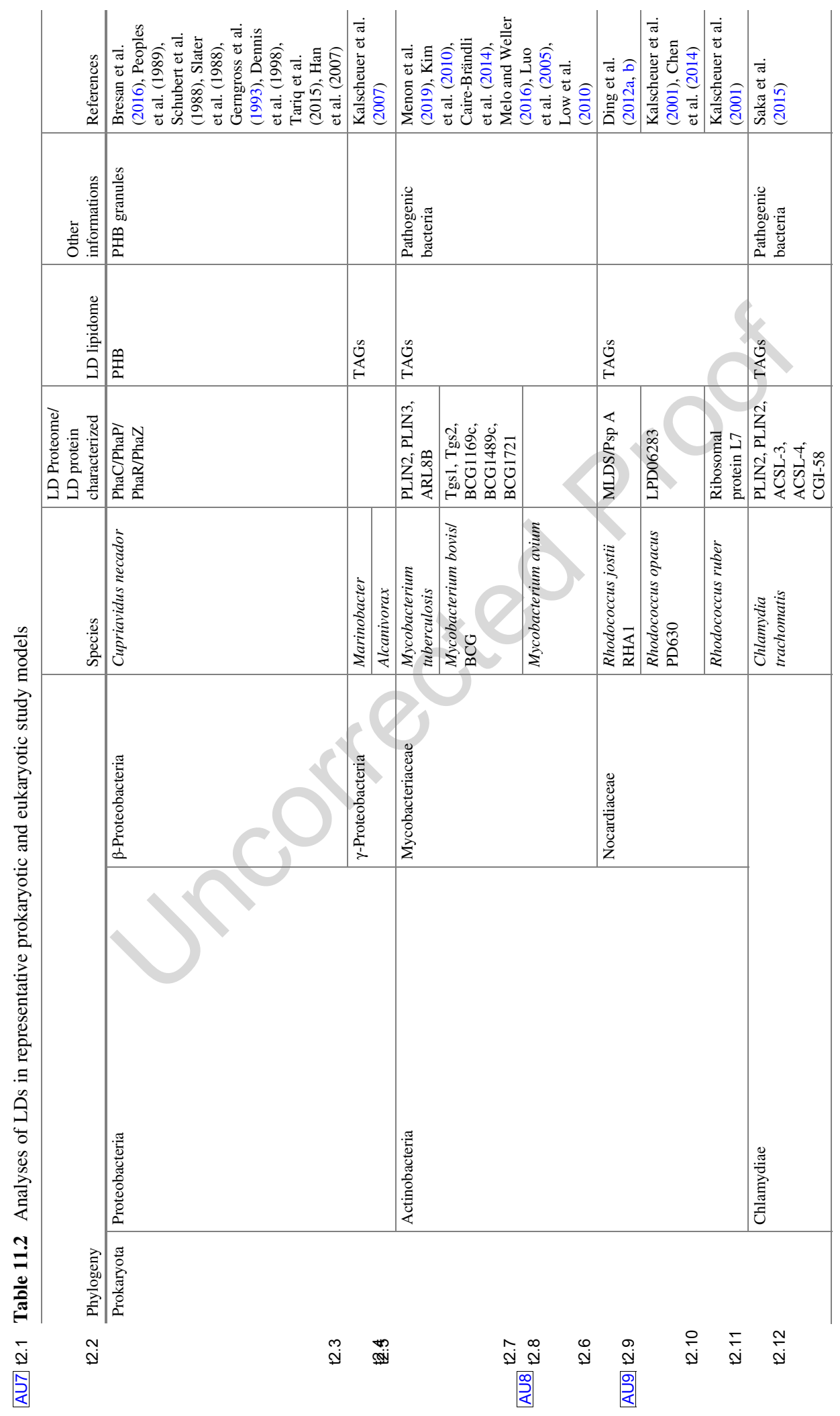


11 The Puzzling Conservation and Diversification of Lipid Droplets from Bacteria...

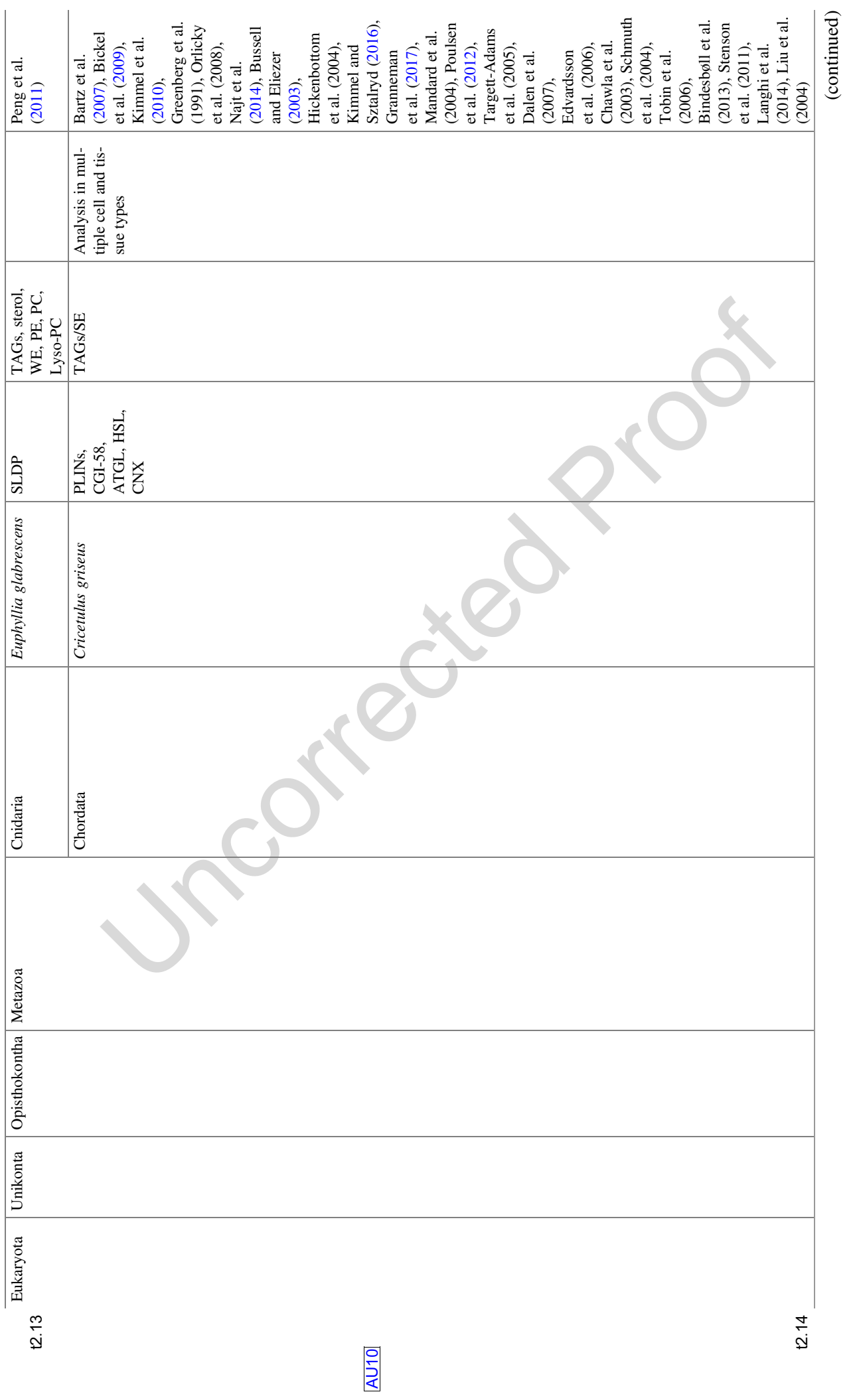




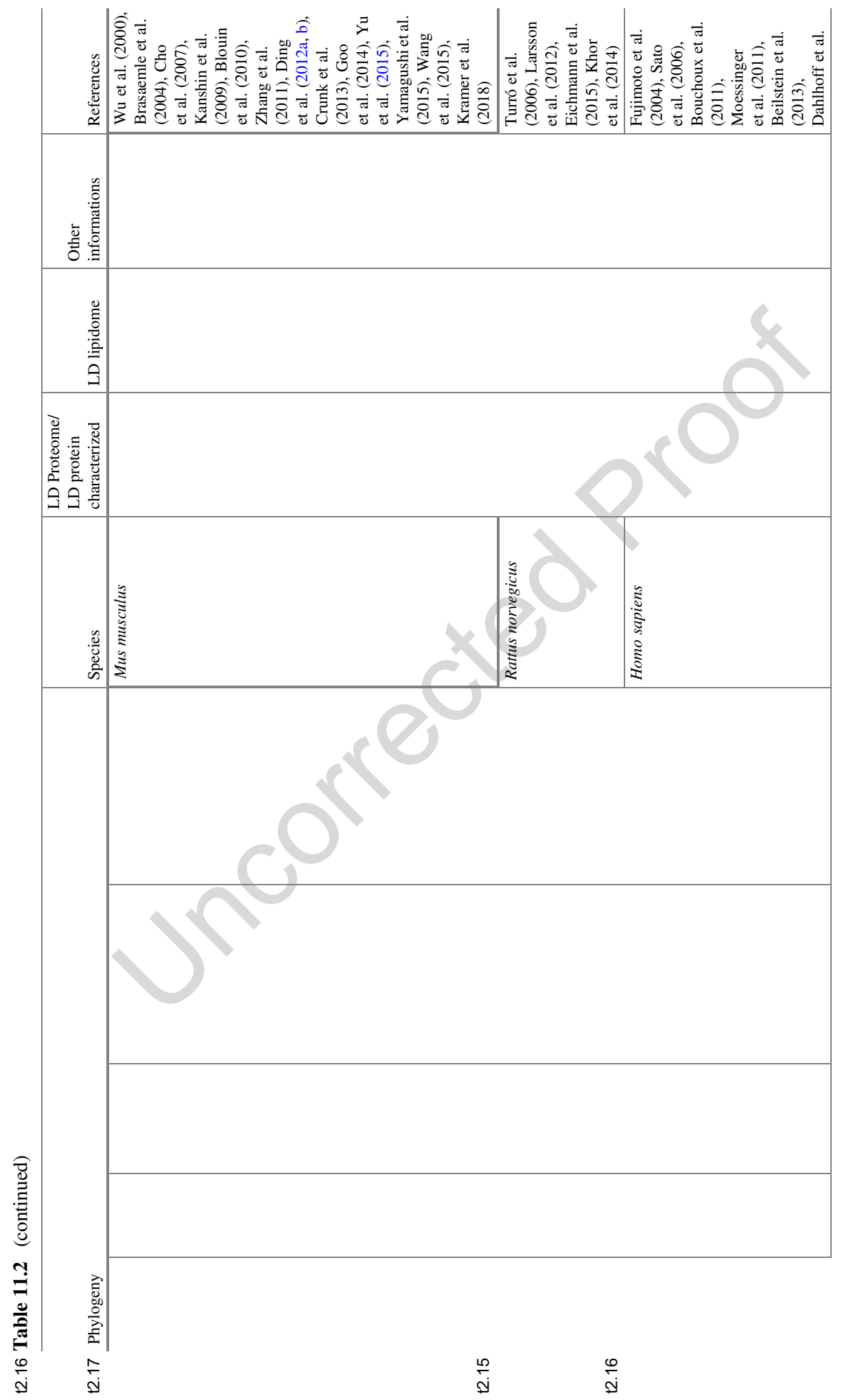


11 The Puzzling Conservation and Diversification of Lipid Droplets from Bacteria...

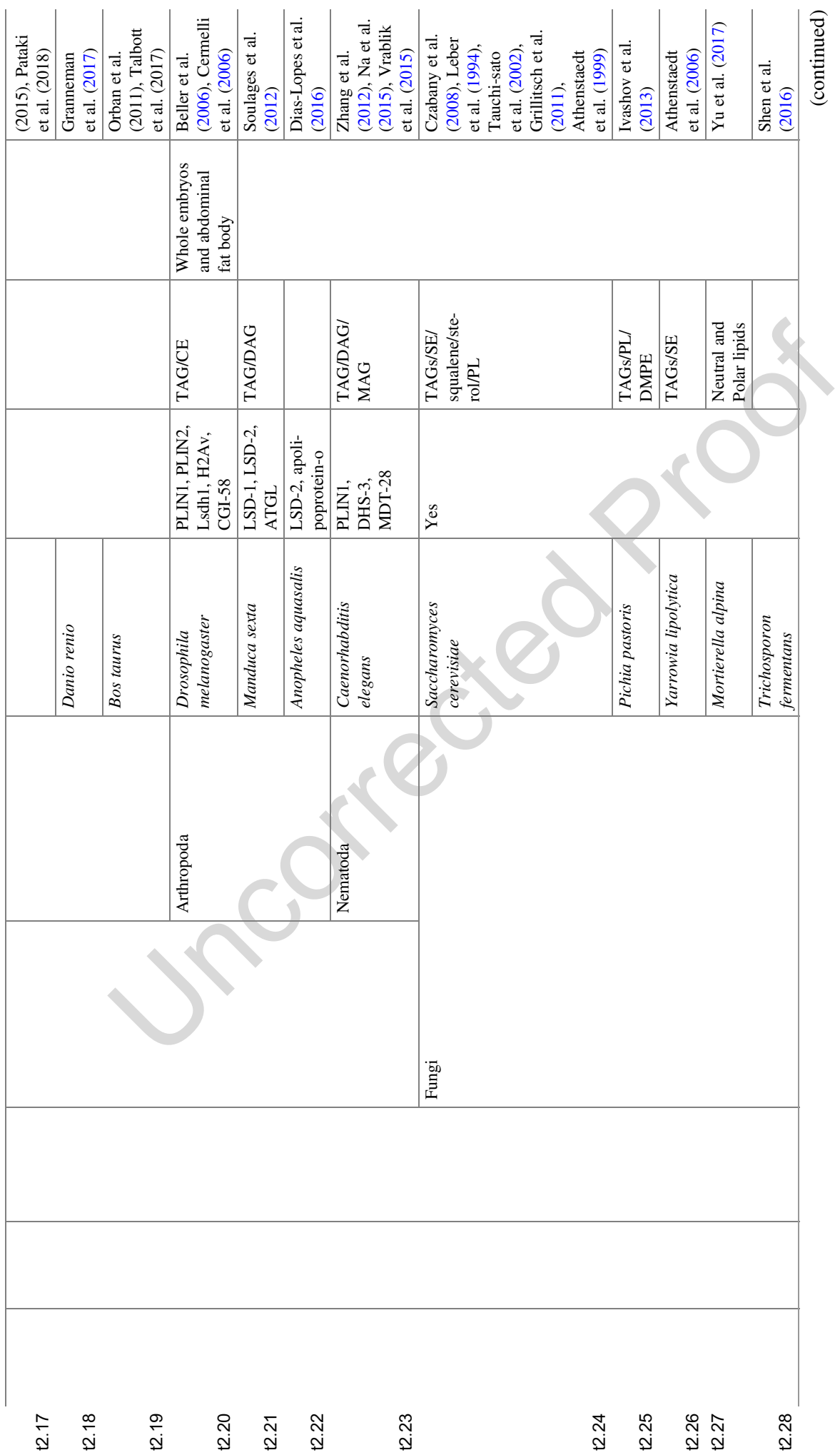




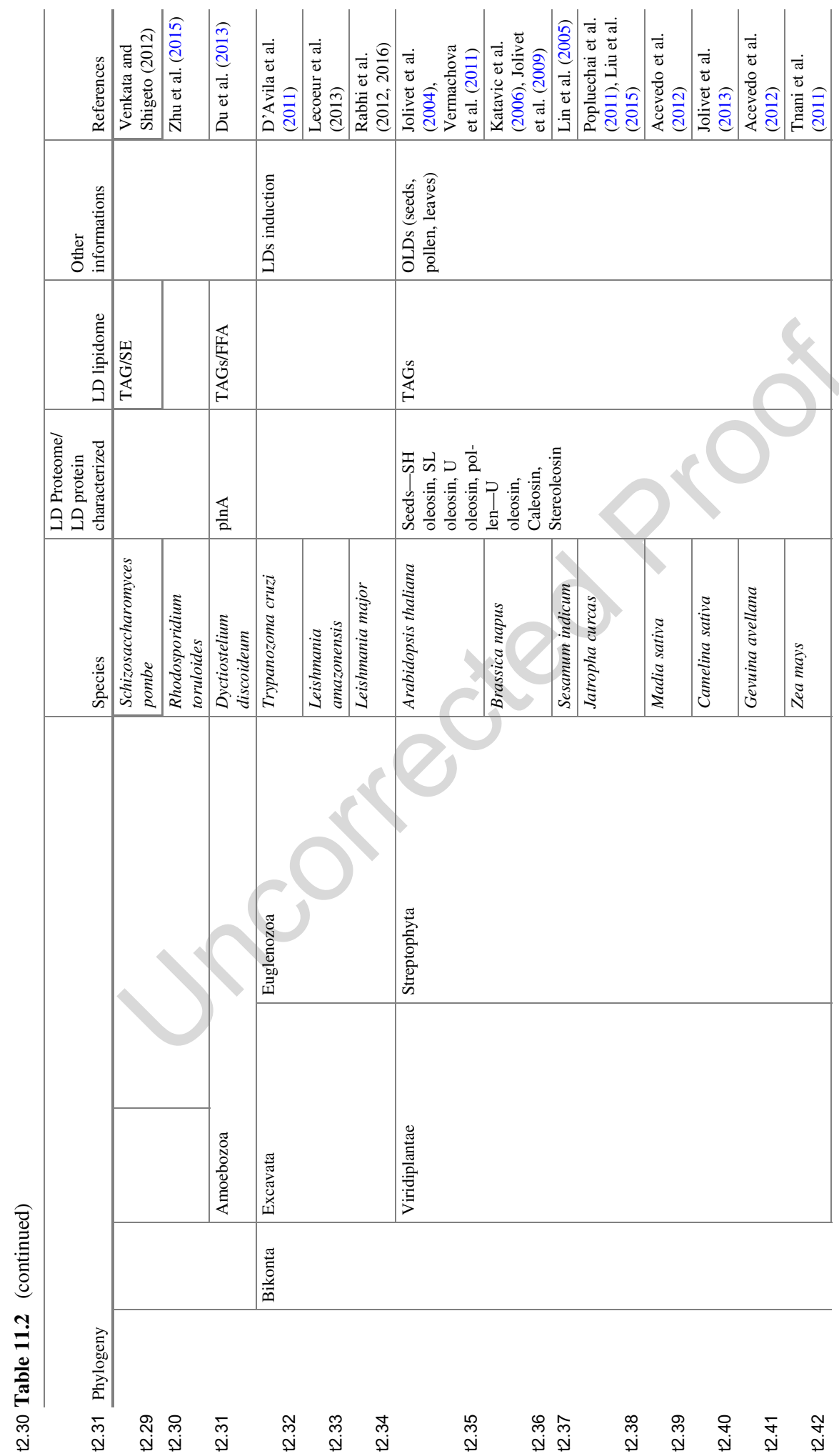


11 The Puzzling Conservation and Diversification of Lipid Droplets from Bacteria...

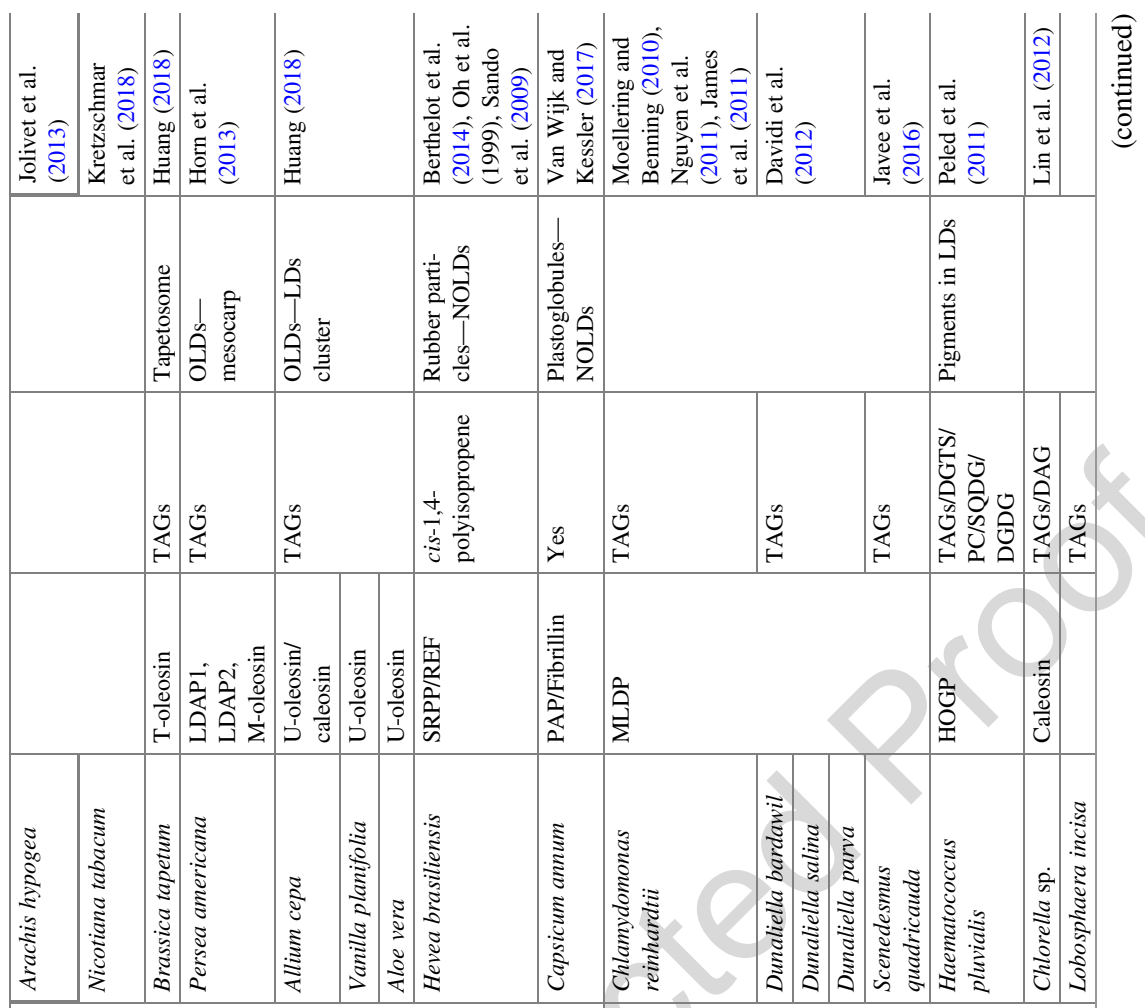




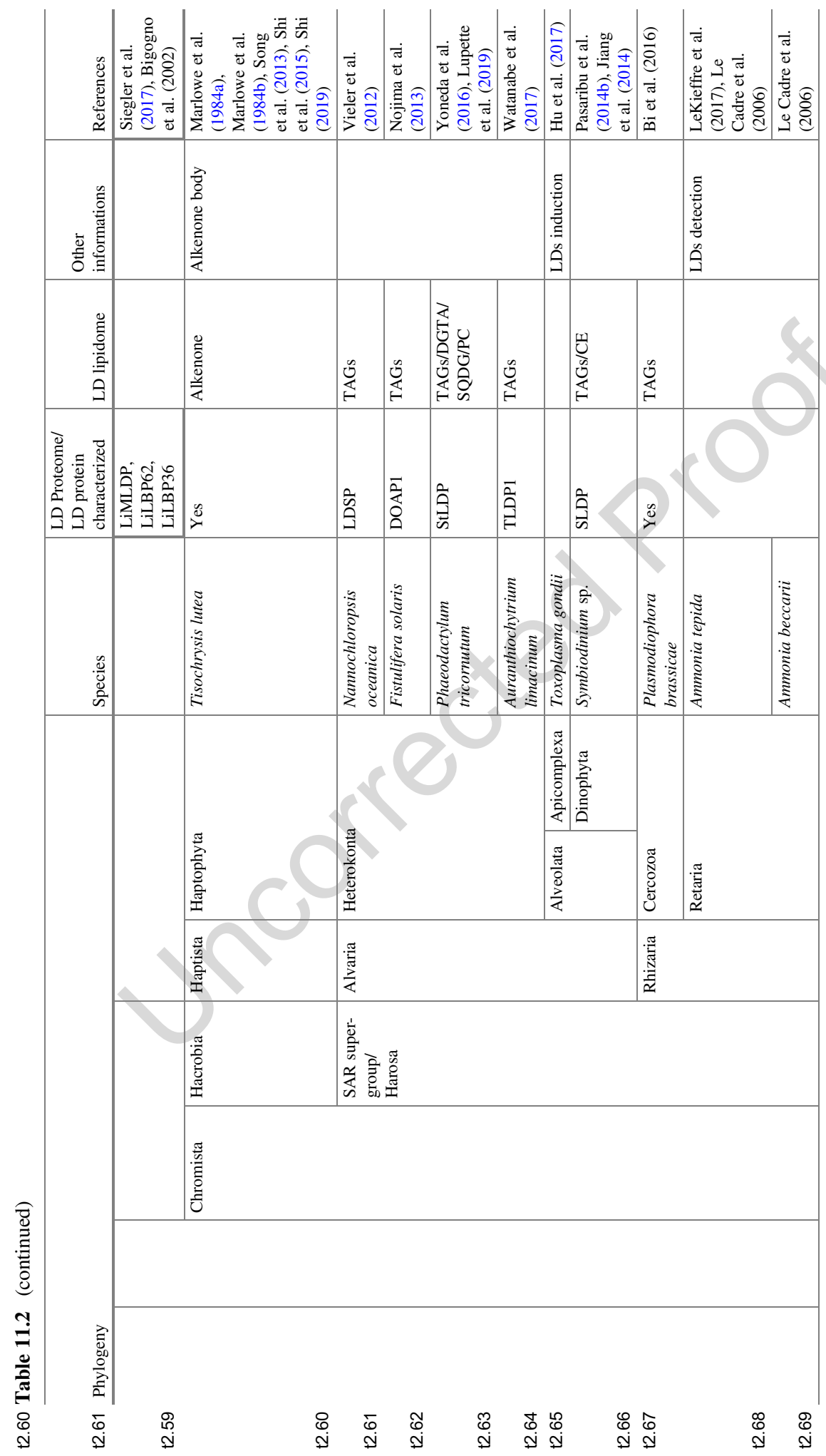


PLIN family (DmPLIN1 and DmPLIN2) in the fat body abdominal, as well as the 376 CGI-58 protein in the whole embryo proteome. As a result, Drosophila has been 377 considered an interesting model for studying the role of LDs in the context of human 378 pathologies. The conservation of LD-associated proteins is not complete, since 379 PLIN3, PLIN4, and PLIN5 appear to be restricted to vertebrates. DmPLIN1 is 380 present only on the surface of LDs and is involved in promotion/prevention mech- 381 anisms for lipolysis (Bi et al. 2012). DmPLIN1 contains four helices in the central 382 region of the protein, capable of binding lipid compounds (Arrese et al. 2008; Lin 383 et al. 2014). Mutant flies deficient of DmPLIN1 have larger LDs. Single and giant 384 LDs within the fat body of these mutants have also been found to confer an obesity 385 phenotype (Beller et al. 2010). DmPLIN2 is present in the cytoplasm and on the 386 surface of LDs (Beller et al. 2010). DmPLIN2 only plays a role in the prevention of 387 lipolysis (Bi et al. 2012). DmPLIN2 mutants have smaller LDs (Li et al. 2012). The 388 double mutant fly DmPLIN1/DmPLIN2 presents a marked reduction of LD size; 389 however, LDs are still present in these mutants suggesting that there is an additional 390 mechanism regulating lipid storage and lipolysis. DmHSL (Hormone-Sensitive- 391 Lipase) is a lipase participating in lipolysis and interacting with DmPLIN1 392 (Bi et al. 2012). A complementary analysis of the CG2254 protein identified in the 393 proteome of LDs from Drosophila abdominal cells (Beller et al. 2006) showed that it 394 was LD subset dehydrogenase 1 (Lsdsh1) (Thul et al. 2017). 395

Interestingly, the study of Drophila LDs has highlighted an unsuspected role in 396 the homeostasis of histones within the cell, a function that may be more frequent in 397 eukaryotes than initially thought. Histones were first identified in the LD proteome 398 of Drosophila embryos (Cermelli et al. 2006). These histones are not detected in the 399 fat body abdominal proteome (Beller et al. 2006). These results were confirmed by a 400 secondary study of the Jabba protein that co-immuno-precipitates with histones 401 (Li et al. 2012). The presence of histones H2A, H2B, and H4 was also observed in 402 the tobacco sphinx Manduca sexta (Soulages et al. 2012). Finally, it has recently 403 been shown that histone H2Ay was dynamically associated with D. melanogaster 404 LD during cleavage and syncytial blastoderm stages (Johnson et al. 2018). 405

A recent study also investigated the protein ABHD4/ABHD5 (CGI-58) in Dro- 406 sophila (Hehlert et al. 2019). The mutation of the pummelig (puml) gene encoding 407 CGI-58 causes abnormal accumulation of TAG in mutant flies as well as a change in 408 the FA profile of TAGs in Malpighian tubules (kidneys). In contrast to mammals, the 409 Drosophila puml does not stimulate ATGL lipase activity (brummer) in vitro 410 (Hehlert et al. 2019). $\quad 411$

Proteomic studies of LDs have also been performed in other arthropod models 412 such as the tobacco sphinx Manduca sexta (Soulages et al. 2012) or Anopheles 413 aquasalis (Dias-Lopes et al. 2016), an important vector of Plasmodium virax, the 414 main human malarial parasite in the Americas.

The nematode Caenorhabditis elegans is a worm constituting a popular study model 417 for the study of apoptosis, embryonic development, and cellular aging. This 418 
nematode has LDs measuring $1-1.5 \mu \mathrm{m}$ in diameter in its intestine and in the hypodermis. Three proteomic studies of $C$. elegans LDs have been performed (Zhang et al. 2012; Na et al. 2015; Vrablik et al. 2015). The first shotgun proteomic analysis allowed the identification of 306 proteins of which 193 were known to be associated with mammalian LDs (Zhang et al. 2012). This first study identified the DHS-3 protein on the surface of the LD via a GFP fusion. A second proteome of the LD of C.elegans allowed the identification of 154 proteins of which 113 are common with the first proteome (Na et al. 2015). DHS-3 and MDT-28 are the two major proteins in $C$. elegans LD. The deletion of the $d h s-3$ gene causes a decrease in the size of LDs as well as the amount of their TAG. The $m d t-28$ mutant causes the formation of LD aggregations (Na et al. 2015). A third proteome compared the LD protein composition of a C. elegans wild type and high daf-2 (e1370) fat mutant (Vrablik et al. 2015). Using a GFP construct, the ACS-4 protein, an acyl-CoA synthase, was localized at the surface of the $C$. elegans LD. It has long been thought that PLINs were lost in C. elegans. However, three isoforms of mammalian PLINs have been identified: PLIN-1a, PLIN-1b, and PLIN-1c. These isoforms have an $\mathrm{N}$-terminal PAT domain, an amphiphilic region with imperfect helices, and four C-terminal helices (Chughtai et al. 2015). The C. elegans genome seems to also code for several sequences of the LD protein actors ABHD4 (CeLid-1) and ABHD5/CGI58 (CeAbhd5.2) (Lee et al. 2014; Xie and Roy 2015).

\section{Fungi}

Saccharomyces cerevisiae is a widely used model for studying lipid biology because the synthetic pathways in the ER are similar to those of plants and animals (Koch et al. 2014). LDs measure about $400 \mathrm{~nm}$ in this organism. The hydrophobic core of LDs of $S$. cerevisiae is composed of TAGs grouped in the center and surrounded by the steryl ester molecules (Leber et al. 1994; Czabany et al. 2008). There is also a minor proportion of squalene and sterols. The monolayer of phospholipids consists of PC, PI, PE, PA, and PS (Tauchi-Sato et al. 2002; Grillitsch et al. 2011). The proteome of the LD highlighted proteins that contribute to the synthesis of the hydrophobic core, such as sterol- $\Delta 24$-methyltransferase, squalene epoxidase, and lanosterol synthetase (Leber et al. 1994; Athenstaedt et al. 1999) (Table 11.2). In Pichia pastoris, the polar lipid monolayer is mainly composed of PC and PE but there is also a lower proportion of PI, PS, PA, cardiolipin, lysophospholipids, and 1,2-dimyristoyl-sn-glycero-3-phosphoethanolamine (DMPE) (Ivashov et al. 2013) (Table 11.2). Studies have also been conducted in other models such as Yarrowia lipolytica (Athenstaedt et al. 2006), Mortierella alpina (Yu et al. 2017), Cryptococcus albidus (Shi et al. 2013), Trichosporon fermentans (Shen et al. 2016), Schizosaccharomyces pombe (Noothalapati Venkata and Shigeto 2012), or Rhodosporidium toruloides (Zhu et al. 2015). Identified proteins comprise a majority of orthologues of $S$. cerevisiae and one can deduce from this analysis the enzymatic functions related to the synthesis of ergosterol, phospholipids, sphingolipids, but 
also proteins involved in the metabolism of fatty acids and degradation of non-polar 460 lipids (Table 11.2).

\subsubsection{Amoebozoa}

Only one study of LD was recorded for Amoebozoa in the model species 463 Dyctyostelium discoideum. D. discoideum is an amoeba living on dead leaves in 464 forests, phagocyting bacteria, or yeasts (Malchow et al. 1967). LDs of D. discoideum 465 are composed of TAG, free fatty acid, and more than $10 \%$ of an unknown lipid 466 (Table 11.2). Proteomic analysis of the LD of D. discoideum reveals 72 proteins 467 including one perilipin (plnA) (Du et al. 2013). The expression of plnA in CHO cells 468 allowed their localization to the surface of LDs (Miura et al. 2002). Fifteen lipid 469 metabolism enzymes, 31 small GTPases belonging to the Rab family, eleven 470 endoplasmic reticulum component proteins, and six cytoskeletal associated proteins 471 were also identified.

In non-photosynthetic eukaryotes, LD studies support the general conservation of 473 the architecture including some classes of perilipins, but with a striking diversifica- 474 tion of proteins associated with the LDs likely associated with specialized functions. 475 A role in histone homeostasis may be an important innovation in eukaryotes. The 476 biogenesis process from the ER seems also conserved, with SEIPIN-associated 477 machineries. Enzymes involved in the biosynthesis of TAGs, also lipases and pro- 478 teins involved in lipolysis, such as CGI-58, seem to be the markers of LD evolution. 479 However, the molecular function of CGI-58 seems to differ in the various clades of 480 non-photosynthetic eukaryotes studied so far, a functional 'flexibility' which is also 481 observed in photosynthetic eukaryotes (see below).

\subsubsection{Photosynthetic Eukaryotes Originating from Primary Endosymbiosis}

The acquisition of the primary chloroplast occurred when an unknown eukaryotic 485 organism integrated a Gram-negative cyanobacterium (Petroutsos et al. 2014; 486 Maréchal 2018). This event led to the emergence of a photosynthetic organelle 487 with two membranes (inner and outer membranes of the envelope) called the plastid. 488 Based on the machinery of photosynthetic pigments (Archibald and Keeling 2002; 489 Petroutsos et al. 2014; Maréchal 2018), three lineages appeared. The green lineage of 490 primary endosymbionts corresponds to Viridiplantae. This lineage includes 491 Chlorophyta ("green algae") and Streptophyta (commonly called "plants"). The 492 photosynthetic machinery is composed of chlorophyll a and b. The red lineage of 493 primary endosymbionts consists of Rhodophyta or "red algae". These organisms 494 have chlorophylls a and c associated with phycobilin. The 'blue' lineage of primary 495 endosymbionts corresponds to Glaucocystophytes (Cyanophora paradoxa), having 496 a chloroplast with a residual cell wall rich in peptidoglycans. Chlorophyll a is 497 associated with phycocyanin and allophycocyanin. Primary endosymbiosis has 498 
long been considered a unique event during evolution. The study of Paulinella chromatophora (a photosynthetic amoeba) has shown that a second, more recent, primary endosymbiosis event (60-100 million years ago) occurred between cyanobacteria and an amoeba (Maréchal 2018). This endosymbiosis led to the formation of an organelle also limited by two membranes, called the chromatophore.

In contrast to non-photosynthetic eukaryotes, in which FA biosynthesis occurs in the cytosol, FAs are synthesized in the stroma of the chloroplast and then exported to the cytosol. On the one hand, chloroplasts contain LD, called plastoglobules. On the other hand, the plastid appears to play a role in the production of TAG and biogenesis of cytosolic LDs in some of the lineages of photosynthetic eukaryotes. Stronger cooperation of the ER and plastid in LD formation may therefore be an important innovation in these primary endosymbionts. This may also be related to the loss of perilipins and the emergence of specific LD-associated proteins. Our understanding of LD evolution in primary endosymbionts is mainly based on analyses performed in Chlorophyta and land plants (Embryophyta, mostly in Angiosperms).

\section{Chlorophyta}

Chlamydomonas reinhardtii is a green alga that accumulates oils in the form of LDs following environmental stresses such as a nitrogen deficiency or an increase in salinity. A proteomic study of LD performed in C. reinhardtii highlighted a Major Lipid Droplet Protein (MLDP) of $27 \mathrm{kDa}$ (Moellering and Benning 2010; James et al. 2011; Nguyen et al. 2011). The phenotype of a mldp mutant suggests that MLDP is involved in the regulation of LD size (Moellering and Benning 2010). A $33 \mathrm{kDa}$ homolog of MLDP was also found in Haematococcus pluvialis (Peled et al. 2011) as well as in three Dunaliella species (Davidi et al. 2012). MLDP was also detected in Scenedesmus quadricauda during salt stress or nitrogen deficiency (Javee et al. 2016). MLDP orthologues are also present in several species of Chlorophyta: Volvox carteri, Haematococcus pluvialis, Dunaliella salina, Coccomyxa sp., Chlorella variabilis, Polytomella parva, Prototheca wickerhamii, and Micromonas pusilla CCMP1545 (Goold et al. 2015). A $28 \mathrm{kDa}$ caleosin protein was shown to be the major protein in the LD of Chlorella sp. (Lin et al. 2012). The size of LDs of Chlorella can reach $3 \mu \mathrm{m}$ (Lin et al. 2012). The caleosin localization was specifically determined on the surface of the LD by immunostaining with gold beads (Pasaribu et al. 2014a). In these studies, caleosins first characterized in plants (see below) seem to be conserved LD-associated proteins.

\section{Plantae}

Plants accumulate LDs in both vegetative and reproductive tissues (Chapman et al. 2012). The involvement of LDs in the physiology and development of plants are currently little known. The LD proteins of plants are divided into three functional 
groups: (1) oleosins; (2) caleosins, steroleosins, and dioxygenases; and (3) the pro- 538 teins associated with the LD.

Oleosins were the first proteins characterized on the surface of LDs of Zea mays 540 seeds (Qu et al. 1986; Vance and Huang 1987). By their small molecular weight 541 (15-26 kDa), oleosins are very abundant proteins on the surface of LDs of plants. 542 Structurally, the oleosins are divided into three portions: (1) a short and amphiphilic 543 $\mathrm{N}$-terminal peptide, (2) a C-terminal amphiphilic peptide of varying length, and (3) a 544 hydrophobic pin of nonpolar amino acids penetrating the monolayer of phospho- 545 lipids on the surface of the LD (Huang 2018). The N- and C-terminal peptides form 546 receptor binding lipases and other proteins involved in TAG degradation (Huang and 547 Huang 2015). The 72 amino acid pin is a specificity of oleosins (Kory et al. 2016), 548 thus differing from major LD proteins of mammals (PLINs 1-6) or bacteria (Phasin). 549 The pin is also divided into three portions, consisting of two 30-amino acid arms 550 connecting a loop consisting of three prolines (P) and one serine (S) forming a 551 structure called the "Proline Knot" inserted into the hydrophobic core [19, 229]. The 552 secondary structure of the loop has not been defined yet. Seventeen genes code for 553 the oleosins in Arabidopsis: five in the seed, three jointly in the seeds and pollen 554 grains, and nine in the floral cells of the tapetum [230]. 555

In a bioinformatic study, oleosins could be classified into six major lineages 556 (Huang and Huang 2015): the primitive lineage evolving from green algae to 557 Filicophyta (ferns), the universal lineage (U oleosin) for which genes are present, 558 and Bryophyta (mosses) to higher plants. The universal U line then evolved to 559 specialize in particular structures such as seed-specific oleosins with the Low and 560 High Molecular Weight Seed Oleosin (SH) lines in Angiosperms. Oleosins also 561 specialized in Brassicaceae with the tapetum T line and the M line for oleosins in the 562 Lauraceae mesocarp (avocado) (Kilaru et al. 2015).

Caleosins, stereoleosins, and dioxygenases are grouped into a single cluster 564 because they have a common enzymatic function in the stress response (Huang 565 2018). Caleosins are enzymes that have been found in microsomes (Frandsen et al. 566 1996). Caleosins, like oleosins, have a hydrophobic as well as a "proline knot" motif 567 (Huang 2018). A recent study showed that two of the hairpin prolines (P116 and 568 P125) were not essential for LD binding (Müller et al. 2016). Caleosins have an 569 N-terminal EF hand-type calcium binding motif (Chen et al. 1999), a peroxygenase 570 activity (Hanano et al. 2006), and several phosphorylation sites. The genome of 571 Arabidopsis thaliana codes for eight caleosins expressed in different structures 572 (Shimada and Hara-Nishimura 2015).

Steroleosins (sterol dehydrogenases) have only two structural domains: a hydro- 574 phobic N-terminal region and a C-terminal region having a sequence close to the 575 mammalian hydroxysteroid dehydrogenase (HSD) domain. Steroleosins also have a 576 semi-conserved hydrophobic pin similar to that of oleosin, but of a size similar to 577 that of caleosin (Huang 2018). They are also class I proteins such as oleosins and 578 caleosins (Kory et al. 2016). In contrast to oleosins and caleosins, steroleosins do not 579 have a "proline knot" motif but a "proline knob" (Chapman et al. 2012). Steroleosins 580 are particularly studied because they are capable of converting sterols into 581 brassinosteroids (Baud et al. 2009), a class of phytohormones. 
Dioxygenases $(\alpha-\mathrm{DOX})$ have also recently been found to be associated with LDs in leaves of senescent Arabidopsis thaliana cells (Shimada et al. 2014). A. thaliana has two homologs of these dioxygenases (At $\alpha-\mathrm{DOX} 1$ and At $\alpha-\mathrm{DOX} 2)$. At $\alpha-\mathrm{DOX} 1$ is localized on LDs of leaves and At $\alpha$-DOX2 is located in the ER (Shimada et al. 2014). These enzymes produce an oxylipin (2-HOT) from $\alpha$-linolenic acid (18:3). These molecules participate in defense mechanisms in response to biotic and abiotic stresses (Shimada and Hara-Nishimura 2015).

Not all LD proteins listed above belong to the same LDs. Indeed, in plants, cytosolic LDs are divided into two groups: oleosin-based lipid droplets (OLDs) and non-oleosin-based lipid droplets (NOLDs) (Laibach et al. 2015).

Seeds are the most studied structure for the understanding of OLDs because they are able to accumulate TAGs in the form of LDs reserve to support germination after the end of the dormancy phase (Huang 1996). In special cases such as jojoba seed (Simmondsia chinensis), LDs can contain cerides (Yermanos 1975). These LDs are small (between 0.5 and $1.5 \mu \mathrm{m}$ ) conferring a large surface area per unit of TAGs, facilitating the binding of lipases during germination (Huang and Huang 2015). Numerous proteomic studies have been performed in plant models: Brassica napus (Katavic et al. 2006; Jolivet et al. 2009), Arabidopsis thaliana (Jolivet et al. 2004; Vermachova et al. 2011), Sesamum indicum (Lin et al. 2005), Jatropha curcas (Popluechai et al. 2011; Liu et al. 2015), Madia sativa (Acevedo et al. 2012), Gevuina avellana (Acevedo et al. 2012), Zea mays (Tnani et al. 2011), Camelina sativa (Jolivet et al. 2013), or Arachis hypogaea (Jolivet et al. 2013). These proteomic analyses show that LDs are covered with oleosins with a minor presence (less than 5\%) of caleosin and steroleosin (Chapman et al. 2012; Murphy 2012). Oleosins are involved in regulating the size and stability of LDs of seeds (Chapman et al. 2012). LDs have also been characterized in the tapetum cells of the anther (Hsieh and Huang 2004) and in pollen grains and pollen tubes (Kretzschmar et al. 2018). A focused study on PUX10 (Plant UBX Domain-containing Protein 10) whose localization was confirmed by fusion with enhanced GFP (eGFP) on the surface of LDs during embryonic development, seed germination, and pollen tubes, showed that PUX10 recruits by its UBX domain an AAA-type ATPase Cell Cycle 48 (CDC48) that facilitates the transfer of polyubiquitinated protein to the $26 \mathrm{~S}$ proteasome (Kretzschmar et al. 2018).

LDs are also present in Arabidopsis thaliana leaves. The number of LDs is very low in healthy leaves. LDs accumulate more in the leaves in the senescence phase (Shimada et al. 2015) with a variable size of 1-18 $\mu \mathrm{m}$ (Lersten et al. 2006). In particular, the expression of A. thaliana caleosin-3 as well as At $\alpha$-DOX1 increases during senescence (Shimada et al. 2014). Proteomic analysis of the LD of aging leaves of A. thaliana was performed: 28 proteins including 9 enzymes involved in the secondary defense metabolism of the plant were identified (Brocard et al. 2017). The analysis also revealed the presence of the Small Rubber Particle 1 (AtSRP1) protein. Functional analysis of AtSRP1 reveals that this protein modulates the expression of caleosin-3 in aging leaves. In addition, overexpression of AtSRP1 induces an increase in 18:3 enriched TAG accumulations from galactolipid recycling of thylakoids (Brocard et al. 2017). 
LDs of the fruit mesocarp can reach sizes of 10-20 $\mu \mathrm{m}$, placing them at the top of 628 the ranking of the largest observable LDs in eukaryotic cells (Horn et al. 2013). 629 Proteomic analysis of the mesocarp of the avocado (Persea americana) allowed the 630 identification of two LDAP1 and LDAP2 associated proteins (Lipid Droplet- 631 Associated Proteins 1 and 2), which also showed homologies of sequences with 632 Small Rubber Particle Proteins (SRPP) (Horn et al. 2013). Type M oleosins specific 633 to the Lauraceae family have been described in avocado (Huang 2018). 634

NOLDs include two special cases: rubber particles and plastoglobules. More than 635 20,000 species of higher plants can accumulate rubber particles within their vegeta- 636 tive organs (Hagel et al. 2008). Hevea brasiliensis is the main source of latex used by 637 humans. Latex is a colloidal white suspension composed of rubbery and non-rubbery 638 particles, organelles, proteins, lipids, carbohydrates, and minerals. These particles 639 have a hydrophobic core consisting of cis-1,4-polyisopropene surrounded by a 640 monolayer of phospholipids in which proteins are bound (Berthelot et al. 2014). 641 The proteome of the rubber particles revealed two major proteins: the SRPP and the 642 Rubber Elongation Factor (Sando et al. 2009). 643

Finally, plastoglobules are special LDs synthesized inside the chloroplast 644 (Bréhélin et al. 2007). Plastoglobules are continuous with the outer monolayer of 645 thylakoids in higher plants, which is supposed to facilitate the exchange of metab- 646 olites (Van Wijk and Kessler 2017). Plastoglobules have been less studied than 647 cytosolic LDs. Analyses support that they have a hydrophobic core containing three 648 classes of molecules: (1) neutral lipids (TAGs, phytol esters, and free fatty acids), 649 (2) tocopherols and quinones ( $\alpha$-tocopherol, plastoquinol-9, plastochromanol-8, and 650 Vitamin $\mathrm{K}_{1}$ ), and (3) linear carotenoids (lycopene), cyclic carotenoids (lutein and 651 xanthophylls), and carotenoid esters (Van Wijk and Kessler 2017). These molecules 652 are surrounded by a monolayer of amphiphilic lipids (monogalactosyldiacylglycerol, 653 MGDG; digalactosyldiacylglycerol, DGDG; sulfoquinovosyldiacylglycerol, 654 SQDG) in which proteins are embedded. Proteomic analyses of several study models 655 (the chromoplast of red pepper Capsicum annuum and the green microalgae 656 Dunaliella bardawil and Chlamydomonas reinhardtii) have allowed the identifica- 657 tion of about 30 proteins (Kreimer 2009; Davidi et al. 2015). The protein mainly 658 represented on the surface of plastoglobules is Plastid-lipid Associated Protein, 659 Fibrillin (PAP/Fibrillin) (Youssef et al. 2010). This 30-kDa protein does not have 660 transmembrane segments.

\subsubsection{Photosynthetic Eukaryotes and Non-photosynthetic Relatives Originating from a Secondary Endosymbiosis}

Secondary endosymbioses are events that have occurred several times during the 664 evolution of eukaryotes (Petroutsos et al. 2014). Two main types of lineages have 665 emerged as a result of these evolutionary events: (1) green lines resulting from the 666 integration of a green alga within an unknown heterotrophic eukaryotic organism, 667 leading to the appearance of Euglenozoa and Chlororarachniophytes and (2) the red 668 
lines resulting from the integration of a red alga inside a eukaryotic organism forming the polyphyletic group of Chromalveolata.

\section{Organisms from the Green Lineage: Euglenozoa}

At least two independent events of secondary endosymbiosis between a green alga and an unknown heterotrophic eukaryotic organism led to the appearance of Euglenozoa and Chlororarachniophytes (Petroutsos et al. 2014; Füssy and Oborník 2018). Chlororarachniophytes (Bigelowiella natans) contain a four-membrane chloroplast and a residual nucleus, called the nucleomorph, located between the two most internal and external membranes of the chloroplast (Petroutsos et al. 2014). To our knowledge, no data are available on LD formation in Chlororarachniophytes. Euglenozoa comprises photosynthetic species with a chloroplast bounded by three membranes but also parasitic species devoid of any chloroplast (Petroutsos et al. 2014). Several studies report that parasitic organisms such as Trypanosoma cruzi, the agent of Chagas disease (D'avila et al. 2011), are capable of inducing the formation of large LDs in macrophages. In photosynthetic organisms, Euglena gracilis is a microalga living in freshwater, interesting for the research of alternatives to petroleum resources because it accumulates wax esters inside LDs in nitrogen starvation. These wax esters come from the conversion of a crystalline $\beta$-1,3-glucan, paramylon. Wax esters can be used as fuel for aviation but also as biofuel after refining (Guo et al. 2017). To our knowledge, there is no detailed study of the structure of the LD of E. gracilis.

\section{Organisms from the Red Lineage: Chromista/Chromalveolates}

\section{Apicomplexa (Containing a Non-photosynthetic Plastid)}

Apicomplexa is a phylum grouping unicellular parasitic organisms responsible for many diseases in metazoans such as malaria or toxoplasmosis. As noted previously with pathogenic bacteria, parasitic Euglenozoa or HCV parasites, these organisms are also able to divert the lipid metabolism of the host by inducing the formation of LDs or by modifying their architecture. One of the most commonly studied Apicomplexa models is Toxoplasma gondii, the toxoplasmosis agent. T. gondii replicates in mammalian cells in a parasitophorous vacuole. Toxoplasma induces an increase in the catalytic activity of the host DGAT, which leads to diversion of lipid metabolism toward TAGs and guarantees the import of FAs (Hu et al. 2017).

\section{Dinophyta}

Dinophyta or Dinoflagellates are photosynthetic protists, but also mixotrophic and heterotrophic, with two flagella allowing them to move (Sardet 2013). There are symbiotic forms of Dinoflagellates, especially with corals. LDs are present in hosts 
and symbionts of coral-dinoflagellate endosymbiosis (Kellogg and Patton 1983). 705 The first proteomic analysis of the gastrodermale LDs of Euphyllia glabrescens 706 (Cnidaria) revealed the presence of 42 proteins involved in the metabolism of lipids 707 and proteins as well as in the response to some stresses (Peng et al. 2011). A second 708 proteomic analysis of LDs of Symbiodinium sp. associated with coral tentacles of 709 Euphyllia glabrescens, highlighted a $20 \mathrm{kDa}$ Symbiodinium Lipid Droplet Protein 710 (SLDP) that plays a role in the structural and functional stability of the LD (Pasaribu 711 et al. 2014b). Proteomic analysis of LDs of isolated Symbiodinium spp. has also been 712 performed (Jiang et al. 2014). This study did not reveal the presence of SLDP but of 713 several proteins involved in lipid metabolism (Sterol transfer family protein), cell 714 signaling (14-3-3 protein, ADP ribolysis factor), stress response (HSP90), and 715 energy metabolism (ATP synthase F1 subunit $\alpha$, GTP binding protein).

\section{Haptophyta}

Haptophyta include photosynthetic species forming extracellular shells of calcium 718 carbonate (coccolithophores' coccospheres) and non-calcified cell walls (Cavalier- 719 Smith 1986). A proteomic study was carried out in the non-calcareous haptophyta 720 Tisochrysis lutea, formerly Isochrysis aff. galbana (Bendif et al. 2013). This 721 microalga is interesting for the aquaculture industry because it is enriched in DHA 722 (Hubert et al. 2017). It is also known to accumulate a particular neutral lipid in place 723 of TAGs: an alkenone, a very long chain ketone $\left(C_{37}\right.$ to $\left.C_{40}\right)$, within an alkenone 724 body (AB) (Marlowe et al. 1984a, b). The purification of LDs highlighted the 725 presence of $74.2 \%$ of alkenone $\left(C_{37}\right.$ and $\left.C_{38}\right), 24.6 \%$ of other lipids, and $1.2 \%$ of 726 alkene. Proteomic analysis revealed the presence of 514 proteins on the surface of 727 T. lutea $\mathrm{AB}$, of which three are predominant: a V-ATPase identified previously in a 728 proteomic analysis in nitrogen deficiency (Song et al. 2013), an SPFH (Stomatin/ 729 Prohibitin/Flotillin/HflK) domain-containing protein, localized in the endoplasmic 730 reticulum, associated with a lipid raft and a hypothetical protein (Shi et al. 2015). 731 With the exception of SPFH, the transition between a rich medium and a low 732 nitrogen medium causes an increase in the expression of the target genes encoding 733 T. lutea AB proteins (Shi 2019).

\section{Heterokonta}

Heterokonta (or Stramenopiles) constitute a superphylum in the Chromista kingdom 736 (Cavalier-Smith 2018). Five proteomic studies were performed in four model spe- 737 cies: Nannochloropsis oceanica (Vieler et al. 2012), Phaeodactylum tricornutum 738 (Yoneda et al. 2016; Lupette et al. 2019), Fistulifera solaris (Nojima et al. 2013), 739 and Aurantiochytrium limacinum (Watanabe et al. 2017). The first study conducted 740 with $N$. oceanica (Vieler et al. 2012) revealed a 16.8 kDa Lipid Droplet Surface 741 Protein (LDSP) by proteomic analysis. This protein is present in the six species of 742 Nannochloropsis with functional features close to plant oleosins as well as MLDP of 743 Chlamydomonas reinhardtii. The second proteomic study in diatoms concerns the 744 pennate diatom Fistulifera solaris (Nojima et al. 2013). The authors did not detect 745 
any major band and the purification seems to involve protein contaminations. By subtracting the protein purification proteins from the soluble fraction, the authors identified fourteen candidate proteins. By searching for conserved domains, one of the identified proteins has a quinoprotein-alcohol dehydrogenase-like domain detected in the proteome of LDs of Camelina sativa seed (Jolivet et al. 2013) but has no hydrophobic domain. This protein of 506 amino acids was named DOAP1 (Diatom-Oleosome-Associated-Protein 1). Based on a fusion between GFP and the $\mathrm{N}$-terminal signal sequence of DOAP1 (Maeda et al. 2014), this protein was initially present in the ER. The third model characterized is the pennate diatom Phaeodactylum tricornutum. A first proteomic study allowed the identification of five major proteins on the surface of the LD of $P$. tricornutum, including the Stramenopile LD Protein (StLDP) (Yoneda et al. 2016). This class I protein was localized to the surface of the LD by fusion with a GFP protein (Yoneda et al. 2018). By optimization of the P. tricornutum LD purification protocol, a second study was carried out in this organism (Lupette et al. 2019). The proteome of the LD is composed of 86 proteins including most notably the LD-protein StLDP, metabolic actors, organelle membrane-associated proteins, proteins implicated in the treatment of genetic information, or chaperones involved in protein quality control. The hydrophobic core is only made of TAG surrounded by a monolayer of polar lipids consisting of PC, SQDG, and two molecular species (20:5-16:1 and 20:5-16:2) of diacylglycerylhydroxymethyltrimethyl- $\beta$-alanine (DGTA), a betaine lipid. A sterol probably located in the polar lipid monolayer, brassicasterol, was also detected and specific enrichment of $\beta$-carotene has been observed (Lupette et al. 2019). A last proteomic study was recently conducted on the model Aurantiochytrium limacinum F26-b, a non-photosynthetic unicellular microalga classified as Heterokonta. This microalga is particularly studied for its biotechnological potential because it is a species rich in DHA (22:6) (Dellero et al. 2018a, b; Morabito et al. 2019). A proteomic study of the LD fraction of A. limacinum F26-b identified a Thraustochytrid-specific Lipid Droplet Protein 1 (TLDP1) (Watanabe et al. 2017). A mutant of tldp1 shows a decrease in the amount of TAG and the number of lipid droplets per cell. However, larger and irregular LDs are observed in this mutant. TLDP1 may regulate the accumulation of TAGs as well as the size and number of LDs in A. limacinum F26-b (Watanabe et al. 2017).

Based on all these analyses of secondary endosymbionts, it appeared that major LD proteins are specific to distinct clades and that their origin needs to be traced in evolution. Lipids associated with the few LDs analyzed to date sometimes include plastid lipids together with ER lipids, suggesting cooperation of these two organelles in LD biogenesis. Detection of lipases, often associated with mitochondrial and/or lysosomal processes, further suggests a conserved role of mitochondria and lysosomes in the mobilization of FAs deriving from TAG stored in cytosolic LDs. 


\subsection{Lipid Droplets Are Dynamic Structures}

LDs are dynamic subcellular structures, most often transient, rarely stable. Their 787 development includes an intense phase of biosynthesis of the hydrophobic molecules 788 that constitute its core (anabolism) and the biosynthesis and the arrangement of the 789 barrier located at the periphery (a monolayer of polar lipids, most often 790 phosphoglycerolipids, and proteins, either embedded in this monolayer or associated 791 more or less transiently).

\subsubsection{Anabolism of PHA and TAG}

\subsubsection{PHA Biosynthesis}

PHA biosynthesis routes have been recently reviewed by Możejko-Ciesielska and 795 Kiewisz (2016). Depending on the length of the PHA chain, several pathways exist. 796 For short-chain PHA, a direct pathway involves three enzymes: a $\beta$-ketothiolase 797 (PhaA), an acetoacetyl-CoA reductase (PhaB), and a PHA synthase (PhaC). For 798 medium chain PHA, several pathways are possible: (1) a synthetic pathway involv- 799 ing $\beta$-oxidation resulting in the formation of R-3-hydroxyacyl-CoA that is converted 800 by PhaC to PHA; (2) a synthetic route involving elongation of acetyl-CoA, via de 801 novo synthesis of fatty acids; and (3) a synthetic route generating precursors of 802 3-hydroxyacyl-CoA.

\subsubsection{TAG Biosynthesis}

The hydrophobic core of LDs described in eukaryotes contains predominantly 805 TAGs. The synthesis of TAGs can be carried out by two main pathways at the 806 level of the endoplasmic reticulum (the so-called "eukaryotic" pathway): (1) an acyl- 807 CoA dependent pathway commonly referred to as the Kennedy pathway (Fig. 11.2), 808 (2) an acyl-CoA independent pathway involving phosphatidylcholine (PC) as an 809 acyl donor, and (3) a specific route of synthesis of TAGs in the chloroplast.

\subsubsection{Biogenesis of the Lipid Droplet}

\subsubsection{Biogenesis of PHA Granules in Prokaryotes}

There are currently two models for the in vivo formation of PHA granules in 813 prokaryotes: (1) a model based on the formation of micelles of PHA synthases 814 (PhaC) and (2) a model based on the budding of PHA granules from the cytoplasmic 815 membrane (Pötter and Steinbüchel 2006). The model based on the formation of 816 
micelles of PHB synthases is currently the most accepted (Haywood et al. 1989). We do not know if any of these processes has been transferred to a eukaryotic system.

\subsubsection{Biogenesis of Cytosolic TAG Droplets in Eukaryotes}

The general principles of the biogenesis mechanism seem to be similar in non-photosynthetic and photosynthetic organisms (Fig. 11.2-TAG synthesis). The first step consists of the synthesis of TAG at the level of the ER, through the Kennedy pathway (see Sect. 11.3.1.2). Following the synthesis of TAGs, a "lens" of neutral lipids (TAGs and sterol esters) develops within the bilayer of the ER at particular nucleation sites (Fig. 11.2-Nucleation) (Pol et al. 2014; Wilfling et al. 2014). A number of pre-droplets are formed in the ER from freely diffusing TAG molecules, but only a small proportion of them will ultimately form a lipid droplet. The lifespan of these lipid pre-droplets is estimated at a few milliseconds (Khandelia et al. 2010). This phenomenon leads to an energy optimum called a nucleation barrier (Thiam and Forêt 2016). The homogeneity of the phospholipid bilayer of the reticulum is also an important parameter to take into account the success of nucleation. Indeed, on a uniform bilayer, the nucleation of LDs could occur randomly. However, the phospholipid bilayer of the ER is heterogeneous in its biochemical composition. There are therefore specific sites where the nucleation energy is lower. Nucleation can be favored by four different phenomena: (1) the curvature of the membrane developing hydrophobic defects favorable to the accumulation of TAG, (2) the synthesis sites of TAGs defined by the presence of DGATs, or other synthetic enzymes such as PDATs, (3) the presence of proteins (SEIPIN, FIT, PLINs, ACSL) inducing curvature in decreasing the bending energy of the membrane, and (4) the presence of proteins and/or lipids interacting with TAGs (Thiam and Forêt 2016).

Following the formation of this lens, budding (Fig. 11.2—Budding) of the LD occurs on the cytoplasmic side of the ER (Walther et al. 2017). This polarized budding of LDs follows an unknown mechanism. In humans, it has been proposed that an ER protein, FIT2 (Fat-inducing transcript 2), was involved in the polarization of budding (Choudhary et al. 2016). There are currently several models concerning the growth of the $\mathrm{LD}$, including the coalescence and Ostwald ripening (Thiam et al. 2013b). Coalescence is a physical mechanism corresponding to the fusion of two identical substances (in our case, the fusion of two LDs). When an emulsion of oil and water is vigorously mixed, the fusion of LDs with each other is observed to form a giant lipid droplet reflecting the separation between the oil and the water. Ostwald ripening is a destabilization mechanism corresponding to the gradual disappearance of small LDs from an emulsion to give way to larger LDs (Thiam et al. 2013b). This mechanism begins with the transfer of TAG molecules from small LDs to larger ones. The direction of the transfer is dictated by the pressure difference of Laplace (Thiam et al. 2013b; Thiam and Forêt 2016).

An increase in the contact angle between the LD and the ER bilayer causes fission of the LD (Fig. 11.2-Fission). This mechanism also involves proteins on the surface of the reticulum. An interesting candidate is the SEIPIN protein located at 
the level of the ER with two transmembrane domains and a luminal loop (Lundin 859 et al. 2006). SEIPIN is involved functionally in the initial stages of LD formation 860 into generating nascent structures or participating in their maturation in mature LD 861 (Wang et al. 2016). A morphological screen of LDs of Saccharomyces cerevisiae 862 shows that the homolog Fld1 of SEIPIN is necessary for the formation of "normal" 863 droplets (Fei et al. 2008). This protein also participates in the stabilization of the 864 contact sites between the ER and the LD (Salo et al. 2016). A recent study also 865 proposes that the SEIPIN protein and the LDAF1 (Lipid Droplet Assembly Factor 1) 866 protein form an oligomeric complex of approximately $600 \mathrm{kDa}$ in the ER bilayer 867 determining the LD formation sites (Chung et al. 2019). SEIPIN is also involved in 868 the regulation of TAG synthesis: it interacts notably with GPAT, AGAT2, and lipins 869 (phosphatidate phosphatases recruited for the synthesis of DAG, serving as the 870 substrate to the production of TAG). A single Seipin gene is detected in animals 871 and fungi studied so far, whereas three homologs (SEIPIN1, 2, and 3) were reported 872 in higher plant models (Taurino et al. 2017). SEIPINS are divided into two mono- 873 phyletic groups in plants according to their degree of functional specialization (Cai 874 et al. 2015). A functional genetic study shows that double and triple mutations cause 875 the accumulation of larger LDs in Arabidopsis (Taurino et al. 2017). An ortholog of 876 SEIPIN was also detected in the diatom Phaeodactylum tricornutum (Lu et al. 2017). 877 The overexpression of SEIPIN in P. tricornutum causes an increase in the size of 878 LDs, the amount of neutral lipids (57\% increase), and the proportion of saturated 879 fatty acids (16:0) (Lu et al. 2017).

LDs can detach from the ER, forming a population of initial LDs (iLD) measuring 881 $400-800 \mathrm{~nm}$ in diameter (Walther et al. 2017). These LDs can be subsequently 882 converted, according to an unknown mechanism, into a new population of LDs 883 called expanding lipid droplets (eLDs) (Walther et al. 2017). This conversion 884 requires the acquisition of an independent TAG synthesis machinery carried out 885 by GPAT4 and DGAT2 (Kuerschner et al. 2007; Stone et al. 2009; Wilfling et al. 886 2013). These two proteins initially present in the ER are relocated to the LD 887 (Wilfling et al. 2013).

888

Although the conversion mechanism is unknown, there is still evidence that the 889 vesicular machinery ARF1/COP1 (ADP Ribosylation Factor 1/Coat Proteins type I) 890 is involved in this process. In particular, it has been shown in an in vitro system that 891 the ARF1/COP1 machinery allows the synthesis of nano LDs of 60-80 nm (Thiam 892 et al. 2013a). COP1 is a complex composed of seven subunits $\left(\alpha, \beta, \beta^{\prime}, \gamma, \varepsilon, \delta, \zeta\right) 893$ responsible for the retrograde vesicular transport of the Golgi apparatus to the ER as 894 well as intra-Golgi transport (Beck et al. 2009; Jackson 2014). ARF1 is a member of 895 the family of GTP-binding proteins of the Ras superfamily (small GTPases). ARF1 896 is localized in the Golgi apparatus and was initially shown to act in intra-Golgi 897 transport. The role of the ARF1/COP1 system in LD dynamics needs therefore to be 898 clarified further compared to that in Golgi dynamics. 


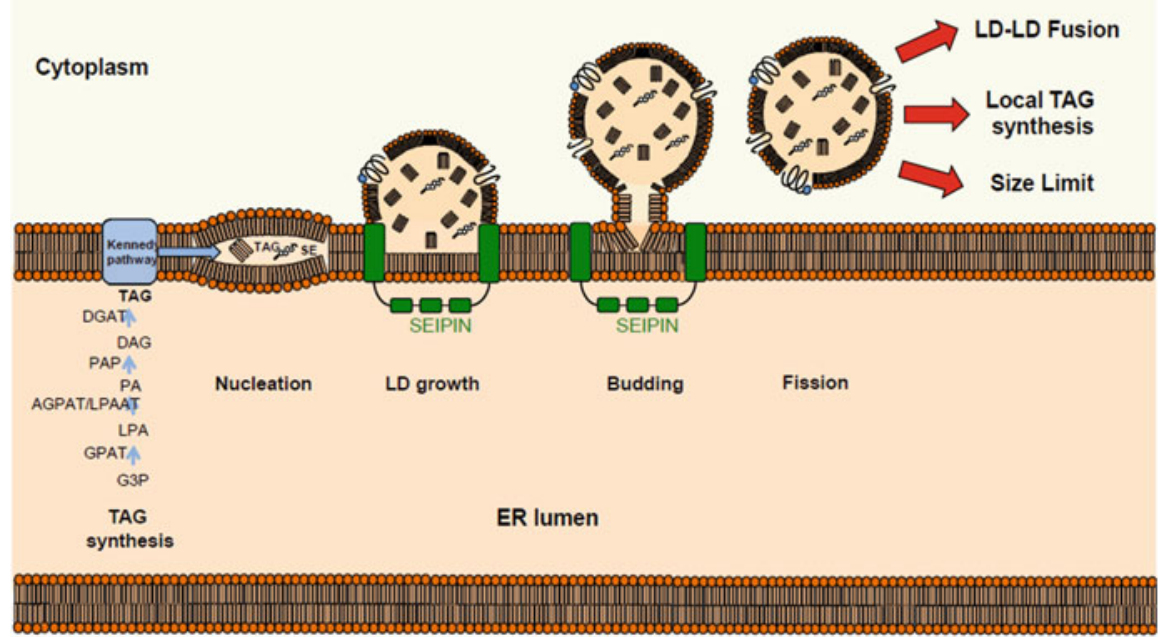

Fig. 11.2 Principles of lipid droplet biogenesis in eukaryotes

\subsubsection{Catabolism of Lipid Droplets}

The catabolism of LDs corresponds to all the degradation reactions of the LD architecture components, e.g. the lipids and hydrophobic components in the core of the LDs and the proteins especially via the ERAD pathway and the 26S proteasome.

\subsubsection{Degradation of PHA in Prokaryotes}

The degradation of PHA granules is carried out by a PHA depolymerase (PhaZ) (Uchino et al. 2008). PhaZ plays a role similar to acyl lipases in eukaryotes (see below). At least two degradation pathways of PHA granules exist: (1) an extracellular pathway in bacteria capable of secreting depolymerases in the environment and (2) an intracellular route, less well known to date. Seven intracellular PHB depolymerases (PhaZ1 to PhaZ7) as well as two PHB hydrolases (PhaY1, PhaY2) have been described in the $R$. eutropha H16 model (Abe et al. 2005; Uchino et al. 2008; Sznajder and Jendrossek 2014). However, PhaZ1 appears to be the only active PHB depolymerase in R. eutropha H16 (Sznajder and Jendrossek 2014). PhaZ1 presents a cysteine in the catalytic site of the "box" lipase. The thiolysis of PHB granules into (R)-3-hydroxybutyryl-CoA by PhaZ1 has been demonstrated (Eggers and Steinbüchel 2013). Localization of PhaZ1 has been confirmed on the surface of PHB granules by fusion with eYFP (Uchino et al. 2008). A mechanistic model of 9 PHB granule degradation was proposed by Eggers and Steinbüchel (2013). 
Multiple processes of TAG hydrolysis have been described in different eukaryotic 922 clades.

In mammals, lipolysis involves different protein actors. The CGI-58 protein 924 interacts with the terminal end of PLIN1a (PLIN1 splice variant) on the surface of 925 the LD in fat cells (Subramanian et al. 2004). The adipose triacylglycerol lipase 926 (ATGL) is also localized at the level of the LD. Before the lipolysis process takes 927 place, the enzymatic activity of ATGL is very low. The majority of ATGL proteins 928 are located in the cytosol before lipolysis occurs. The ATGL activity is inhibited by 929 the G0/G1 switch protein 2 protein (G0S2), attenuating lipolysis in a dose-dependent 930 manner (Schweiger et al. 2012). Lipolysis can be initiated by $\beta$-adrenergic stimula- 931 tion (physical exercise, nutritional deficiency). Adenylate cyclase is activated by a 932 heterotrimeric $G$ protein resulting in the accumulation of cAMP, subsequently 933 activating protein kinase A (PKA) (Viswanadha and Londos 2008). PLIN1 is then 934 phosphorylated by PKA (Granneman et al. 2009). The association of ATGL with 935 LDs is considered to depend on the ARF1/COP1 vesicular machinery (Soni et al. 936 2009). PKA also phosphorylates CGI-58 thus promoting the binding of CGI-58 to 937 ATGL (Sahu-Osen et al. 2015). This process activates ATGL leading to the hydro- 938 lysis of TAGs into DAG and FAs. A Hormone-Sensitive Lipase (HSL) can be 939 activated by phosphorylation: the HSL then binds to the LD, at the level of 940 phosphorylated PLIN1, allowing the conversion of DAG into monoacylglycerol 941 (MAG) and FAs (D'andrea 2016). The HSL/PLIN1 interaction is enhanced by 942 phosphorylation by PKA on several residues of PLIN1: Ser81, Ser222, and 943 Ser276. A monoglyceride lipase (MGL) then completes the release of the last FA 944 and the glycerol backbone. The three released FAs are then transferred to the 945 mitochondria (D’andrea 2016).

LDs are strongly reorganized during lipolysis following a process that reduces 947 their size and increases the surface/volume ratio and accessibility to lipases. Two 948 models exist for the formation of these lipid microdroplets: (1) fragmentation of a 949 giant LD (Moore et al. 2005) and (2) capture of released FAs, which are potentially 950 toxic following lipolysis (Paar et al. 2012). A fat-specific-protein of $27 \mathrm{kDa}$ (FSP27 951 also known as CIDEC for cell death-inducing DNA fragmentation factor alpha-like 952 effector c) binds to ATGL at the surface of LDs inhibiting the lipolysis mechanism 953 by blocking access of CGI-58 to ATGL. A reduction in FSP27 expression by 954 siRNAs in a 3T3-L1 mouse line causes the formation of multiple small LDs as 955 well as an increase in lipolytic activity (Nishino et al. 2008). FSP27 proteins are 956 involved in lipid transfer mechanisms between LDs favoring mechanisms of fusion, 957 growth, and enlargement (Gong et al. 2011; Jambunathan et al. 2011). FSP27 is 958 notably in direct interaction with PLIN1a in white adipose tissues favoring the 959 formation of LDs (Grahn et al. 2013; Sun et al. 2013). The size of LDs therefore 960 seems regulated also by a balance between PLIN1a and FSP27. 
In plants, lipolysis three actors have been described: (1) a Sugar-Dependent Lipase type 1 (SDP1), (2) a homolog of the mammalian protein CGI-58 and (3) a peroxisomal transporter PXA1. These three actors are located at the level of the peroxisome upstream of lipolysis. SDP1 and its SDP1-like homolog (SDP1-L) have been found in the seed of Arabidopsis thaliana (Kelly et al. 2011). This enzyme is able to hydrolyze TAG, DAG, and MAG. SDP1 is a papatin-like lipase (Rydel et al. 2003), homologous to mammalian ATGL, S. cerevisiae TAG lipases (TGL3, TGL4, TGL5) or D. melanogaster BRUMMER protein (Quettier and Eastmond 2009). A homolog of Arabidopsis thaliana SDP1 was also detected in the green alga Lobosphaera incisa (LiSDP1) (Siegler et al. 2017). A fusion with the fluorescent probe $\mathrm{m}$-Venus showed the localization of this lipase at the surface of LDs of L. incisa (Siegler et al. 2017).

A loss of function of the CGI-58 protein in Arabidopsis thaliana results in an abnormal accumulation of LDs in the leaves (Ghosh et al. 2008; James et al. 2010). In addition, the seeds of plants deficient in CGI-58 contain equivalent amounts of neutral lipids, indicating that CGI-58 is not involved in the lipolysis mechanisms of the seed (James et al. 2010). Unlike mammals, the CGI-58 protein does not interact with ATGL lipase in plants but with an ATP-binding cassette (ABC) protein (PXA1) (Park et al. 2013). An ortholog of CGI-58 was found in the genome of the green microalga Chlamydomonas reinhardtii (Merchant et al. 2007). PXA1 (Peroxysomal ABC-Transporter 1) is localized at the level of the peroxisome and transports FAs upstream of their degradation by $\beta$-oxidation (Footitt et al. 2002). It has been estimated that $90 \%$ of FAs transported by PXA1 are provided by SDP1 in combination with the retromeric complex, a multiprotein complex involved in the recycling of transmembrane receptors and retrograde transport of cargo proteins from endosomes to trans-Golgi (Kelly and Feussner 2016). Physical contact between the LD and the peroxisome is negatively correlated with the presence of sucrose (Cui et al. 2016). PXA1 is also involved in the transfer of lipophilic precursors for jasmonate signaling (Theodoulou et al. 2005) and CGI-58 in the regulation of polyamine metabolism (nitrogen metabolism), interacting with spermidine synthase 1 (SPDS1), in plants (Park et al. 2014).

Knowledge of the catabolism of LDs in secondary endosymbionts, containing secondary plastids, is very poor (Kong et al. 2018). A plant SDP1 lipase homolog, TGL1, was found in the diatom Phaeodactylum (Barka et al. 2016). A decrease in its expression causes the accumulation of TAGs. A second actor of catabolism of LDs was discovered in the diatom Thalassiosira pseudonana: CGI-58 (Trentacoste et al. 2013). A decrease in the expression of CGI-58 in Phaeodactylum (antisense line) 1000 study, based on the search for conserved domains and phylogenetic analysis, 1001 identified a putative TAG lipase in Phaeodactylum, called OmTGL (Li et al. 1002 2018). By fusion with a fluorescent protein eGFP, this lipase was shown to localize 1003 in the third outermost membrane of the chloroplast of Phaeodactylum. This locali1004 zation is puzzling as this enzyme is supposed to operate on TAG originating from 1005 cytosolic LDs. It seems that the dynamics of LDs in eukaryotes deriving from 1006 secondary endosymbiosis have very complicated links with multiple membrane 
compartments, including the two outermost membranes of the 4-membrane second1007 ary plastid, the mitochondrial outer envelope membrane, peroxisomes, 1008 autophagosomes, etc. (Lupette et al. 2019).

The $\beta$-oxidation pathway breaks down FAs and produces acetyl-CoA and reducing 1011 power (NADH and $\left.\mathrm{FADH}_{2}\right)($ Houten and Wanders 2010). This pathway occurs in the mitochondrial matrix in Mammalia and/or in the peroxisome (or glyoxysome) in photosynthetic organisms. Short chain fatty acids (less than eight carbons) are degraded in the mitochondria, whereas medium and very long chain fatty acids (greater than eight carbons) are degraded in the peroxisome (Dellero et al. 2018a). Activation and transport of FAs are two preliminary steps required prior $\beta$-oxidation initiation. FA activation is catalyzed by specific long chain acyl-CoA ligases. To reach the mitochondria, an acyl-CoA is 'cargoed' via the carnitine shuttle (Houten and Wanders 2010) in two steps: the acyl-CoA is first converted into acyl-carnitine at the outer mitochondrial membrane by carnitine palmitoyltransferase 1 (CPT1). Acylcarnitine then enters the mitochondrial intermembrane space by passing through a porin and then reaches the internal mitochondrial space via a carnitineacylcarnitine translocase. To reach the peroxisome, transport of acyl-CoA occurs via a specific class of ABC transporter (ATP Binding Cassette).

In both mitochondria and peroxisomes, $\beta$-oxidation occurs by an interactive 1026 process, via the so-called Lynen helix (Houten and Wanders 2010).

\subsubsection{Protein Control and Degradation by the ERAD Pathway and the 26S Proteasome}

An ER localized pathway also regulates the proteins of cytosolic LDs in eukaryotic cells, called the ER associated protein degradation (ERAD) pathway. During translation, and following binding with the signal recognition protein (SRP), polypeptides carrying a signal peptide are imported by a translocon (Sec61 for example) into ER (Rapoport 2007), where they fold and undergo maturation, co- and post-translational modifications (e.g. cleavage of a signal peptide, $\mathrm{N}$-glycosylation, and formation of disulfide bridges). The ERAD machinery is not only a system controlling the quality of proteins targeted to the ER but also a system controlling their quantity (Olzmann et al. 2013a; Stevenson et al. 2016). The presence of mutation, transcription, and translation errors may lead to misfolding, preventing a protein from reaching its functional conformation. The ERAD machinery operates in three stages. First, misfolded or mutated proteins are recognized in the ER. The presence of mismatched cysteine residues, immature glycans, or exposed hydrophobic regions may be targeted by chaperone proteins, such as in the latter case, chaperone proteins of the luminal binding protein (BIP) or cytosolic (Heat Shock Protein 70-Hsp70) (OkudaShimizu and Hendershot 2007). Misfolded proteins are then translocated from the 
1046 ER to the cytosol. Translocation may involve a Valosin-containing-protein (VCP or 1047 p97) in mammals or CDC48 (Cell Cycle Cycle 48 protein) in Saccharomyces 1048 cerevisiae (Meyer et al. 2012). Finally, misfolded protein can be ubiquitinated and 1049 degraded by the $26 \mathrm{~S}$ proteasome (composed of a $20 \mathrm{~S}$ barrel-shaped catalytic core in 1050 the center and two 19S regulatory complexes at each end) (for review, see Sharma 1051 et al. 2016). Multiple LD proteins are controlled by ERAD machinery via a process 1052 that still needs to be fully elucidated (Ruggiano et al. 2016).

1053 ERAD machinery is also involved in the regulation of mammalian TAGs 1054 (Stevenson et al. 2016). UBXD8 (UBX domain-containing protein 8) is an inhibitor 1055 of TAG synthesis when upstream FAs synthesis is very low. An increase in FA 1056 synthesis causes the delivery of a portion of UBDX8 from the ER to the LD, where it 1057 recruits VCP (Valosin-containing protein) to the surface of the droplet (Suzuki et al. 1058 2012; Olzmann et al. 2013b). This mechanism echoes the recruitment of CDC48 1059 (another name of VCP) by PUX10 at the LD of the pollen tube of Nicotiana tabacum 1060 (Kretzschmar et al. 2018). UBXD8 inhibits ATGL on the surface of the LD by 1061 stimulating the dissociation of ATGL from its cofactor CGI-58 (Olzmann et al. 1062 2013b).

1063 A second checkpoint occurs at the DGAT2 level. Treatment with PS-341, a 1064 proteasome inhibitor, reduced the expression of DGAT2 (Oliva et al. 2012). 1065 DGAT2 is a relatively unstable protein, degraded by the $26 \mathrm{~S}$ proteasome after 1066 ubiquitination (Choi et al. 2014). Gp78 (Glycoprotein 78) is an E3 ligase involved 1067 in the ERAD mechanism (Chen et al. 2012). Functional analysis of this protein by 1068 siRNA showed reduction in the ubiquitination of DGAT2 and an increase in its 1069 stabilization (Choi et al. 2014). The transfer of the polyubiquitinated DGAT2 to the 1070 proteasome is carried out by VCP. The role of UBDX8 in the degradation of DGAT2 1071 is currently unknown (Stevenson et al. 2016).

1072 Overall, the ERAD machinery may be a conserved actor of LD homeostasis in 1073 eukaryotes, but our knowledge is even more scarce compared to other regulatory 1074 processes.

\section{11.5 Conclusion and Future Prospects}

1076 This chapter shows that LDs and oil bodies are similar in their general organization 1077 in prokaryotes and eukaryotes. Hydrophobic molecules loaded in their core show a 1078 diversity of chemical structures (PHA, TAG, sterols, carotenoids, alkene, alkenone, 1079 etc.). The PHA granules seem to be restricted to prokaryotes, whereas 1080 TAG-containing LDs are found from bacteria to eukaryotes. The dynamics of LD 1081 formation and homeostasis are exquisitely controlled, indicating the importance of 1082 LDs in cell physiology and development. LDs are therefore essential for cell survival 1083 and development, which is probably one of the reasons for the strong level of 1084 conservation of these subcellular structures. Nevertheless, besides their evident 1085 function as energy storage and carbon reservoirs, the variety of roles harbored by 1086 LDs still needs to be investigated in major eukaryotic clades. It seems that in 
eukaryotes, the ER plays a conserved role as a platform for LD formation, whereas 1087 mitochondria and peroxisome are critical for LD lipid mobilization. The association 1088 of proteins such as histones in LDs analyzed from insects to diatoms suggests that 1089 the LDs may have unexpected functions. LD biogenesis, dynamics, and role are 1090 nevertheless more complex in the organisms deriving from secondary endosymbi- 1091 osis. Only a few LD-associated proteins seem to be conserved in eukaryotes, and 1092 some being involved in LD biogenesis (SEIPIN), TAG biosynthesis, TAG hydro- 1093 lysis coupled with FA export from LDs (CGI-58). The evolution of CGI-58 is 1094 particularly puzzling since this component is involved in TAG mobilization from 1095 LDs, whereas CGI-58 molecular activity has apparently diverged between 1096 non-photosynthetic and photosynthetic clades. In photosynthetic organisms, the 1097 plastid seems to cooperate with the ER in LD biogenesis, possibly in relation to 1098 FA synthesis occurring in the stroma of this organelle, whereas FA synthesis occurs 1099 in the cytosol of non-photosynthetic eukaryotes. In eukaryotes containing secondary 1100 plastids, the role of this organelle may be even more important in LD biogenesis. A 1101 conclusion of this chapter may be a frustrating lack of knowledge, especially in 1102 important branches of the evolution of eukaryotes. Characterizing the molecular 1103 evolution of LD proteins and LD-controlling systems throughout the Tree of Life is a 1104 clear challenge for the future. This effort will be necessary to help explore biodiver- 1105 sity and identify oleaginous species, which may be novel promising resources for a 1106 multitude of applications from food, health to green chemistry and bioenergy. $\quad 1107$

Acknowledgements The authors were supported by the French National Research Agency 1108 (ANR-10-LABEX-04 GRAL Labex, Grenoble Alliance for Integrated Structural Cell Biology; 1109 ANR-11-BTBR-0008 Océanomics; ANR-15-IDEX-02 GlycoAlps) and a Flagship program from 1110 the CEA High Commissioner.

\section{References}

Abe T, Kobayashi T, Saito T (2005) Properties of a novel intracellular poly(3-hydroxybutyrate) 1113 depolymerase with high specific activity (PhaZd) in Wautersia eutropha H16. J Bacteriol 1114 187:6982-6990

Acevedo F, Rubilar M, Shene C, Navarrete P, Romero F, Rabert C, Jolivet P, Valot B, Chardot T 1116 (2012) Seed oil bodies from Gevuina avellana and Madia sativa. J Agric Food Chem 1117 60:6994-7004

Aizaki H, Lee K-J, Sung VMH, Ishiko H, Lai MMC (2004) Characterization of the hepatitis C virus 1119 RNA replication complex associated with lipid rafts. Virology 324:450-461

Alvarez HM (2016) Triacylglycerol and wax ester-accumulating machinery in prokaryotes. 1121 Biochimie 120:28-39

Alvarez H, Steinbüchel A (2002) Triacylglycerols in prokaryotic microorganisms. Appl Microbiol 1123 Biotechnol 60:367-376

Anderson AJ, Dawes EA (1990) Occurrence, metabolism, metabolic role, and industrial uses of 1125 bacterial polyhydroxyalkanoates. Microbiol Rev 54:450-472

Archibald JM, Keeling PJ (2002) Recycled plastids: a 'green movement' in eukaryotic evolution. 1127 Trends Genet 18:577-584 
1129 Arrese EL, Rivera L, Masakazu H, Mirza S, Hartson SD, Weintraub S, Soulages JL (2008) Function 1130 and structure of lipid storage droplet protein 1 studied in lipoprotein complexes. Arch Biochem 1131 Biophys 473:42-47

1132 Athenstaedt K, Zweytick D, Jandrositz A, Kohlwein SD, Daum G (1999) Identification and 1133 characterization of major lipid particle proteins of the yeast Saccharomyces cerevisiae. J 1134 Bacteriol 181:6441-6448

1135 Athenstaedt K, Jolivet P, Boulard C, Zivy M, Negroni L, Nicaud J-M, Chardot T (2006) Lipid 1136 particle composition of the yeast Yarrowia lipolytica depends on the carbon source. Proteomics 1137 6:1450-1459

1138 Barka F, Angstenberger M, Ahrendt T, Lorenzen W, Bode HB, Büchel C (2016) Identification of a 1139 triacylglycerol lipase in the diatom Phaeodactylum tricornutum. Biochim Biophys Acta $1140 \quad 1861: 239-248$

1141 Bartz R, Li W-H, Venables B, Zehmer JK, Roth MR, Welti R, Anderson RGW, Liu P, Chapman 1142 KD (2007) Lipidomics reveals that adiposomes store ether lipids and mediate phospholipid 1143 traffic. J Lipid Res 48:837-847

1144 Baud S, Dichow NR, Kelemen Z, D’andréa S, To A, Berger N, Canonge M, Kronenberger J, 1145 Viterbo D, Dubreucq B, Lepiniec L, Chardot T, Miquel M (2009) Regulation of HSD1 in seeds 1146 of Arabidopsis thaliana. Plant Cell Physiol 50:1463-1478

1147 Beck R, Ravet M, Wieland FT, Cassel D (2009) The COPI system: molecular mechanisms and 1148 function. FEBS Lett 583:2701-2709

1149 Beller M, Riedel D, Jänsch L, Dieterich G, Wehland J, Jäckle H, Kühnlein RP (2006) Character1150 ization of the Drosophila lipid droplet subproteome. Mol Cell Proteomics 5:1082-1094

1151 Beller M, Sztalryd C, Southall N, Bell M, Jäckle H, Auld DS, Oliver B (2008) COPI complex is a 1152 regulator of lipid homeostasis. PLoS Biol 6:e292

1153 Beller M, Bulankina AV, Hsiao H-H, Urlaub H, Jäckle H, Kühnlein RP (2010) PERILIPIN1154 dependent control of lipid droplet structure and fat storage in drosophila. Cell Metab 1155 12:521-532

1156 Bendif EM, Probert I, Schroeder DC, De Vargas C (2013) On the description of Tisochrysis lutea 1157 gen. nov. sp. nov. and Isochrysis nuda sp. nov. in the Isochrysidales, and the transfer of 1158 Dicrateria to the Prymnesiales (Haptophyta). J Appl Phycol 25:1763-1776

1159 Bersuker K, Olzmann JA (2017) Establishing the lipid droplet proteome: mechanisms of lipid 1160 droplet protein targeting and degradation. Biochim Biophys Acta 1862:1166-1177

1161 Berthelot K, Lecomte S, Estevez Y, Zhendre V, Henry S, Thévenot J, Dufourc EJ, Alves ID, Peruch 1162 F (2014) Rubber particle proteins, HbREF and HbSRPP, show different interactions with model 1163 membranes. Biochim Biophys Acta Biomembr 1838:287-299

1164 Bi J, Xiang Y, Chen H, Liu Z, Grönke S, Kühnlein RP, Huang X (2012) Opposite and redundant 1165 roles of the two Drosophila perilipins in lipid mobilization. J Cell Sci 125:3568

1166 Bickel PE, Tansey JT, Welte MA (2009) PAT proteins, an ancient family of lipid droplet proteins 1167 that regulate cellular lipid stores. Biochim Biophys Acta 1791:419-440

1168 Boyer A, Dumans A, Beaumont E, Etienne L, Roingeard P, Meunier J-C (2014) The association of 1169 hepatitis $\mathrm{C}$ virus glycoproteins with apolipoproteins $\mathrm{E}$ and $\mathrm{B}$ early in assembly is conserved in 1170 lipoviral particles. J Biol Chem 289:18904-18913

1171 Brasaemle DL, Wolins NE (2016) Isolation of lipid droplets from cells by density gradient 1172 centrifugation. Curr Protoc Cell Biol 72:3.15.11-13.15.13

1173 Bréhélin C, Kessler F, Van Wijk KJ (2007) Plastoglobules: versatile lipoprotein particles in 1174 plastids. Trends Plant Sci 12:260-266

1175 Bresan S, Sznajder A, Hauf W, Forchhammer K, Pfeiffer D, Jendrossek D (2016) 1176 Polyhydroxyalkanoate (PHA) granules have no phospholipids. Sci Rep 6:26612

1177 Brocard L, Immel F, Coulon D, Esnay N, Tuphile K, Pascal S, Claverol S, Fouillen L, Bessoule J-J, 1178 Bréhélin C (2017) Proteomic analysis of lipid droplets from Arabidopsis aging leaves brings 1179 new insight into their biogenesis and functions. Front Plant Sci 8:894

1180 Bussell R, Eliezer D (2003) A structural and functional role for 11-mer repeats in $\alpha$-synuclein and 1181 other exchangeable lipid binding proteins. J Mol Biol 329:763-778 
11 The Puzzling Conservation and Diversification of Lipid Droplets from Bacteria...

Cai Y, Goodman JM, Pyc M, Mullen RT, Dyer JM, Chapman KD (2015) Arabidopsis SEIPIN 1182 proteins modulate triacylglycerol accumulation and influence lipid droplet proliferation. Plant 1183 Cell 27:2616-2636

Caire-Brändli I, Papadopoulos A, Malaga W, Marais D, Canaan S, Thilo L, De Chastellier C (2014) 1185 Reversible lipid accumulation and associated division arrest of mycobacterium avium in 1186 lipoprotein-induced foamy macrophages may resemble key events during latency and 1187 reactivation of tuberculosis. Infect Immun 82:476-490

Camus G, Herker E, Modi AA, Haas JT, Ramage HR, Farese RV, Ott M (2013) Diacylglycerol 1189 acyltransferase-1 localizes hepatitis C virus NS5A protein to lipid droplets and enhances NS5A 1190 interaction with the viral capsid core. J Biol Chem 288:9915-9923

Castorena KM, Stapleford KA, Miller DJ (2010) Complementary transcriptomic, lipidomic, and 1192 targeted functional genetic analyses in cultured Drosophila cells highlight the role of 1193 glycerophospholipid metabolism in Flock House virus RNA replication. BMC Genomics 1194 11:183-183

Cavalier-Smith T (1986) The kingdom Chromista: origin and systematics. Biopress, Bristol

Cavalier-Smith T (2018) Kingdom Chromista and its eight phyla: a new synthesis emphasising 1197 periplastid protein targeting, cytoskeletal and periplastid evolution, and ancient divergences. 1198 Protoplasma 255:297-357

Cermelli S, Guo Y, Gross SP, Welte MA (2006) The lipid-droplet proteome reveals that droplets are 1200 a protein-storage depot. Curr Biol 16:1783-1795

Chang BH-J, Li L, Paul A, Taniguchi S, Nannegari V, Heird WC, Chan L (2006) Protection against 1202 fatty liver but normal adipogenesis in mice lacking adipose differentiation-related protein. Mol 1203 Cell Biol 26:1063-1076

Chapman KD, Dyer JM, Mullen RT (2012) Biogenesis and functions of lipid droplets in plants: thematic review series: lipid droplet synthesis and metabolism: from yeast to man. J Lipid Res 53:215-226

Chen JC, Tsai CC, Tzen JT (1999) Cloning and secondary structure analysis of caleosin, a unique 1208 calcium-binding protein in oil bodies of plant seeds. Plant Cell Physiol 40:1079-1086 1209

Chen Z, Du S, Fang S (2012) gp78: a multifaceted ubiquitin ligase that integrates a unique protein 1210 degradation pathway from the endoplasmic reticulum. Curr Protein Pept Sci 13:414-424 1211

Chen W, Chang B, Wu X, Li L, Sleeman M, Chan L (2013) Inactivation of Plin4 downregulates 1212 Plin5 and reduces cardiac lipid accumulation in mice. Am J Physiol-Endocrinol Metab 304: 1213 E770-E779

Chen Y, Ding Y, Yang L, Yu J, Liu G, Wang X, Zhang S, Yu D, Song L, Zhang H, Zhang C, 1215 Huo L, Huo C, Wang Y, Du Y, Zhang H, Zhang P, Na H, Xu S, Zhu Y, Xie Z, He T, Zhang Y, 1216 Wang G, Fan Z, Yang F, Liu H, Wang X, Zhang X, Zhang MQ, Li Y, Steinbüchel A, 1217 Fujimoto T, Cichello S, Yu J, Liu P (2014) Integrated omics study delineates the dynamics of 1218 lipid droplets in Rhodococcus opacus PD630. Nucleic Acids Res 42:1052-1064 1219

Choi K, Kim H, Kang H, Lee S-Y, Lee SJ, Back SH, Lee SH, Kim MS, Lee JE, Park JY, Kim J, 1220 Kim S, Song J-H, Choi Y, Lee S, Lee H-J, Kim JH, Cho S (2014) Regulation of diacylglycerol 1221 acyltransferase 2 protein stability by gp78-associated endoplasmic-reticulum-associated degra- 1222 dation. FEBS J 281:3048-3060

Choudhary V, Golden A, Prinz WA (2016) Keeping FIT, storing fat: lipid droplet biogenesis. 1224 Worm 5:e1170276

Chughtai AA, Kaššák F, Kostrouchová M, Novotný JP, Krause MW, Saudek V, Kostrouch Z, 1226 Kostrouchová M (2015) Perilipin-related protein regulates lipid metabolism in C. elegans. PeerJ 1227 3:e1213

Chung J, Wu X, Lambert TJ, Lai ZW, Walther TC, Farese RV (2019) LDAF1 and seipin form a 1229 lipid droplet assembly complex. Dev Cell 51:551-563.e557

Cui S, Hayashi Y, Otomo M, Mano S, Oikawa K, Hayashi M, Nishimura M (2016) Sucrose 1231 production mediated by lipid metabolism suppresses physical interaction of peroxisomes and oil 1232 bodies during germination of Arabidopsis thaliana. J Biol Chem 291:19734-19745 
1234 Czabany T, Wagner A, Zweytick D, Lohner K, Leitner E, Ingolic E, Daum G (2008) Structural and 1235 biochemical properties of lipid particles from the yeast Saccharomyces cerevisiae. J Biol Chem $1236 \quad 283: 17065-17074$

1237 D'avila H, Freire-De-Lima CG, Roque NR, Teixeira L, Barja-Fidalgo C, Silva AR, Melo RCN, 1238 Dosreis GA, Castro-Faria-Neto HC, Bozza PT (2011) Host cell lipid bodies triggered by 1239 Trypanosoma cruzi infection and enhanced by the uptake of apoptotic cells are associated 1240 with prostaglandin E2 generation and increased parasite growth. J Infect Dis 204:951-961

1241 D'andrea S (2016) Lipid droplet mobilization: the different ways to loosen the purse strings. 1242 Biochimie 120:17-27

1243 Davidi L, Katz A, Pick U (2012) Characterization of major lipid droplet proteins from Dunaliella. 1244 Planta 236:19-33

1245 Davidi L, Levin Y, Ben-Dor S, Pick U (2015) Proteome analysis of cytoplasmatic and plastidic $\beta$ 1246 carotene lipid droplets in Dunaliella bardawil. Plant Physiol 167:60-79

1247 Dellero Y, Cagnac O, Rose S, Seddiki K, Cussac M, Morabito C, Lupette J, Aiese Cigliano R, 1248 Sanseverino W, Kuntz M, Jouhet J, Maréchal E, Rébeillé F, Amato A (2018a) Proposal of a new 1249 thraustochytrid genus Hondaea gen. nov. and comparison of its lipid dynamics with the closely 1250 related pseudo-cryptic genus Aurantiochytrium. Algal Res 35:125-141

1251 Dellero Y, Rose S, Metton C, Morabito C, Lupette J, Jouhet J, Maréchal E, Rébeillé F, Amato A 1252 (2018b) Ecophysiology and lipid dynamics of a eukaryotic mangrove decomposer. Environ 1253 Microbiol 20:3057-3068

1254 Den Brok MH, Raaijmakers TK, Collado-Camps E, Adema GJ (2018) Lipid droplets as immune 1255 modulators in myeloid cells. Trends Immunol 39:380-392

1256 Dias-Lopes G, Borges-Veloso A, Saboia-Vahia L, Padrón G, De Faria Castro CL, Guimarães ACR, 1257 Britto C, Cuervo P, De Jesus JB (2016) Proteomics reveals major components of oogenesis in 1258 the reproductive tract of sugar-fed Anopheles aquasalis. Parasitol Res 115:1977-1989

1259 Ding Y, Wu Y, Zeng R, Liao K (2012a) Proteomic profiling of lipid droplet-associated proteins in 1260 primary adipocytes of normal and obese mouse. Acta Biochim Biophys Sin 44:394-406

1261 Ding Y, Yang L, Zhang S, Wang Y, Du Y, Pu J, Peng G, Chen Y, Zhang H, Yu J, Hang H, Wu P, 1262 Yang F, Yang H, Steinbüchel A, Liu P (2012b) Identification of the major functional proteins of 1263 prokaryotic lipid droplets. J Lipid Res 53:399-411

1264 Du X, Barisch C, Paschke P, Herrfurth C, Bertinetti O, Pawolleck N, Otto H, Rühling H, Feussner I, 1265 Herberg FW, Maniak M (2013) Dictyostelium lipid droplets host novel proteins. Eukaryot Cell $1266 \quad 12: 1517-1529$

1267 Eggers J, Steinbüchel A (2013) Poly(3-hydroxybutyrate) degradation in Ralstonia eutropha H16 is 1268 mediated stereoselectively to (S)-3-hydroxybutyryl coenzyme a (CoA) via crotonyl-CoA. J 1269 Bacteriol 195:3213-3223

1270 Faucher P, Poitou C (2016) Physiopathologie de l'obésité. Rev Rhum Monogr 83:6-12

1271 Fei W, Shui G, Gaeta B, Du X, Kuerschner L, Li P, Brown AJ, Wenk MR, Parton RG, Yang H 1272 (2008) Fld1p, a functional homologue of human seipin, regulates the size of lipid droplets in 1273 yeast. J Cell Biol 180:473-482

1274 Footitt S, Slocombe SP, Larner V, Kurup S, Wu Y, Larson T, Graham I, Baker A, Holdsworth M 1275 (2002) Control of germination and lipid mobilization by COMATOSE, the Arabidopsis homo1276 logue of human ALDP. EMBO J 21:2912-2922

1277 Frandsen G, Müller-Uri F, Nielsen M, Mundy J, Skriver K (1996) Novel plant Ca-binding protein 1278 expressed in response to abscisic acid and osmotic stress. J Biol Chem 271:343-348

1279 Füssy Z, Oborník M (2018) Complex endosymbioses I: from primary to complex plastids, multiple 1280 independent events. In: Maréchal E (ed) Plastids: methods and protocols. Springer, New York, 1281 pp 17-35

1282 Gaunt ER, Zhang Q, Cheung W, Wakelam MJO, Lever AML, Desselberger U (2013) Lipidome 1283 analysis of rotavirus-infected cells confirms the close interaction of lipid droplets with 1284 viroplasms. J Gen Virol 94:1576-1586

1285 Georgieva D, Schmitt V, Leal-Calderon F, Langevin D (2009) On the possible role of surface 1286 elasticity in emulsion stability. Langmuir 25:5565-5573 
Gerngross TU, Reilly P, Stubbe J, Sinskey AJ, Peoples OP (1993) Immunocytochemical analysis of 1287 poly-beta-hydroxybutyrate (PHB) synthase in Alcaligenes eutrophus H16: localization of the 1288 synthase enzyme at the surface of PHB granules. J Bacteriol 175:5289-5293 1289

Ghosh AK, Ramakrishnan G, Chandramohan C, Rajasekharan R (2008) CGI-58, the causative gene 1290 for Chanarin-Dorfman syndrome, mediates acylation of lysophosphatidic acid. J Biol Chem 1291 283:24525-24533

Gidda SK, Park S, Pyc M, Yurchenko O, Cai Y, Wu P, Andrews DW, Chapman KD, Dyer JM, 1293 Mullen RT (2016) Lipid droplet-associated proteins (LDAPs) are required for the dynamic 1294 regulation of neutral lipid compartmentation in plant cells. Plant Physiol 170:2052-2071 1295

Gocze PM, Freeman DA (1994) Factors underlying the variability of lipid droplet fluorescence in 1296 MA-10 leydig tumor cells. Cytometry 17:151-158

Gong J, Sun Z, Wu L, Xu W, Schieber N, Xu D, Shui G, Yang H, Parton RG, Li P (2011) Fsp27 1298 promotes lipid droplet growth by lipid exchange and transfer at lipid droplet contact sites. J Cell 1299 Biol 195:953-963

Goold H, Beisson F, Peltier G, Li-Beisson Y (2015) Microalgal lipid droplets: composition, diversity, biogenesis and functions. Plant Cell Rep 34:545-555

1300

1301

1302

Grahn THM, Zhang Y, Lee M-J, Sommer AG, Mostoslavsky G, Fried SK, Greenberg AS, Puri V 1303 (2013) FSP27 and PLIN1 interaction promotes the formation of large lipid droplets in human 1304 adipocytes. Biochem Biophys Res Commun 432:296-301 1305

Granneman JG, Moore H-PH, Krishnamoorthy R, Rathod M (2009) Perilipin controls lipolysis by 1306 regulating the interactions of $\mathrm{AB}$-hydrolase containing 5 (Abhd5) and adipose triglyceride 1307 lipase (Atgl). J Biol Chem 284:34538-34544 1308

Granneman JG, Kimler VA, Zhang H, Ye X, Luo X, Postlethwait JH, Thummel R (2017) Lipid 1309 droplet biology and evolution illuminated by the characterization of a novel perilipin in teleost 1310 fish. elife 6:e21771

Greenspan P, Mayer EP, Fowler SD (1985) Nile red: a selective fluorescent stain for intracellular lipid droplets. J Cell Biol 100:965-973

Grillitsch K, Connerth M, Köfeler H, Arrey TN, Rietschel B, Wagner B, Karas M, Daum G (2011) 1314 Lipid particles/droplets of the yeast Saccharomyces cerevisiae revisited: lipidome meets prote- 1315 ome. Biochim Biophys Acta 1811:1165-1176

Gromova M, Guillermo A, Bayle P-A, Bardet M (2015) In vivo measurement of the size of oil 1317 bodies in plant seeds using a simple and robust pulsed field gradient NMR method. Eur Biophys 1318 J 44:121-129

Guo Y, Walther TC, Rao M, Stuurman N, Goshima G, Terayama K, Wong JS, Vale RD, Walter P, 1320 Farese RV (2008) Functional genomic screen reveals genes involved in lipid-droplet formation 1321 and utilization. Nature 453:657-661

Guo B, Lei C, Ito T, Yaxiaer Y, Kobayashi H, Jiang Y, Tanaka Y, Ozeki Y, Goda K (2017) High- 1323 throughput label-free screening of euglena gracilis with optofluidic time-stretch quantitative 1324 phase microscopy. SPIE BiOS 12

Hagel JM, Yeung EC, Facchini PJ (2008) Got milk? The secret life of laticifers. Trends Plant Sci 1326 13:631-639

Hanano A, Burcklen M, Flenet M, Ivancich A, Louwagie M, Garin J, Blée E (2006) Plant seed 1328 peroxygenase is an original heme-oxygenase with an EF-hand calcium binding motif. J Biol 1329 Chem 281:33140-33151

Harchouni S, Field B, Menand B (2018) AC-202, a highly effective fluorophore for the visualiza- 1331 tion of lipid droplets in green algae and diatoms. Biotechnol Biofuels 11:120 1332

Haywood GW, Anderson AJ, Dawes EA (1989) The importance of PHB-synthase substrate 1333 specificity in polyhydroxyalkanoate synthesis by Alcaligenes eutrophus. FEMS Microbiol 1334 Lett 57:1-6

Hehlert P, Hofferek V, Heier C, Eichmann TO, Riedel D, Rosenberg J, Takaćs A, Nagy HM, 1336 Oberer M, Zimmermann R, Kühnlein RP (2019) The $\alpha / \beta$-hydrolase domain-containing 4- and 1337 5-related phospholipase Pummelig controls energy storage in Drosophila. J Lipid Res 1338 60:1365-1378 
1340 Henne WM, Reese ML, Goodman JM (2018) The assembly of lipid droplets and their roles in 1341 challenged cells. EMBO J 37

1342 Horn PJ, James CN, Gidda SK, Kilaru A, Dyer JM, Mullen RT, Ohlrogge JB, Chapman KD (2013) 1343 Identification of a new class of lipid droplet-associated proteins in plants. Plant Physiol $1344 \quad 162: 1926-1936$

1345 Houten SM, Wanders RJA (2010) A general introduction to the biochemistry of mitochondrial fatty 1346 acid $\beta$-oxidation. J Inherit Metab Dis 33:469-477

1347 Hsieh K, Huang AHC (2004) Endoplasmic reticulum, oleosins, and oils in seeds and tapetum cells. 1348 Plant Physiol 136:3427-3434

$1349 \mathrm{Hu}$ X, Binns D, Reese ML (2017) The coccidian parasites Toxoplasma and Neospora dysregulate 1350 mammalian lipid droplet biogenesis. J Biol Chem 292:11009-11020

1351 Huang AH (1996) Oleosins and oil bodies in seeds and other organs. Plant Physiol 110:1055-1061

1352 Huang AHC (2018) Plant lipid droplets and their associated proteins: potential for rapid advances 1353 ([OPEN]). Plant Physiol 176:1894-1918

1354 Huang M-D, Huang AHC (2015) Bioinformatics reveal five lineages of oleosins and the mechanism 1355 of lineage evolution related to structure/function from green algae to seed plants. Plant Physiol $1356 \quad 169: 453-470$

1357 Hubert F, Poisson L, Loiseau C, Gauvry L, Pencréac'h G, Hérault J, Ergan F (2017) Lipids and 1358 lipolytic enzymes of the microalga Isochrysis galbana. OCL 24:D407

1359 Ikari N, Shimizu A, Asano T (2018) Lysosomal acid lipase deficiency in Japan: a case report of 1360 siblings and a literature review of cases in Japan. J Nippon Med Sch 85:131-137

1361 Imai Y, Varela GM, Jackson MB, Graham MJ, Crooke RM, Ahima RS (2007) Reduction of 1362 hepatosteatosis and lipid levels by an adipose differentiation-related protein antisense oligonu1363 cleotide. Gastroenterology 132:1947-1954

1364 Imamura M, Inoguchi T, Ikuyama S, Taniguchi S, Kobayashi K, Nakashima N, Nawata H (2002) 1365 ADRP stimulates lipid accumulation and lipid droplet formation in murine fibroblasts. Am J 1366 Physiol-Endocrinol Metab 283:E775-E783

1367 Ivashov VA, Grillitsch K, Koefeler H, Leitner E, Baeumlisberger D, Karas M, Daum G (2013) 1368 Lipidome and proteome of lipid droplets from the methylotrophic yeast Pichia pastoris. 1369 Biochim Biophys Acta 1831:282-290

1370 Jackson LP (2014) Structure and mechanism of COPI vesicle biogenesis. Curr Opin Cell Biol $1371 \quad 29: 67-73$

1372 Jambunathan S, Yin J, Khan W, Tamori Y, Puri V (2011) FSP27 promotes lipid droplet clustering 1373 and then fusion to regulate triglyceride accumulation. PLoS One 6:e28614

1374 James CN, Horn PJ, Case CR, Gidda SK, Zhang D, Mullen RT, Dyer JM, Anderson RGW, 1375 Chapman KD (2010) Disruption of the Arabidopsis CGI-58 homologue produces Chanarin1376 Dorfman-like lipid droplet accumulation in plants. Proc Natl Acad Sci USA 107:17833-17838 1377 James GO, Hocart CH, Hillier W, Chen H, Kordbacheh F, Price GD, Djordjevic MA (2011) Fatty 1378 acid profiling of Chlamydomonas reinhardtii under nitrogen deprivation. Bioresour Technol $1379 \quad 102: 3343-3351$

1380 Javee A, Sulochana SB, Pallissery SJ, Arumugam M (2016) Major lipid body protein: a conserved 1381 structural component of lipid body accumulated during abiotic stress in S. quadricauda CASA1382 CC202. Front Energy Res 4

1383 Jiang P-L, Pasaribu B, Chen C-S (2014) Nitrogen-deprivation elevates lipid levels in 1384 Symbiodinium spp. by lipid droplet accumulation: morphological and compositional analyses. 1385 PLoS One 9:e87416

1386 Johnson MR, Stephenson RA, Ghaemmaghami S, Welte MA (2018) Developmentally regulated 1387 H2Av buffering via dynamic sequestration to lipid droplets in Drosophila embryos. elife 7: 1388 e36021

1389 Jolivet P, Roux E, D'andrea S, Davanture M, Negroni L, Zivy M, Chardot T (2004) Protein 1390 composition of oil bodies in Arabidopsis thaliana ecotype WS. Plant Physiol Biochem $1391 \quad 42: 501-509$ 
11 The Puzzling Conservation and Diversification of Lipid Droplets from Bacteria...

Jolivet P, Boulard C, Bellamy A, Larré C, Barre M, Rogniaux H, D'andréa S, Chardot T, Nesi N 1392 (2009) Protein composition of oil bodies from mature Brassica napus seeds. Proteomics 1393 9:3268-3284

Jolivet P, Acevedo F, Boulard C, D'andréa S, Faure J-D, Kohli A, Nesi N, Valot B, Chardot T 1395 (2013) Crop seed oil bodies: from challenges in protein identification to an emerging picture of 1396 the oil body proteome. Proteomics 13:1836-1849

Kalscheuer R, Wältermann M, Alvarez H, Steinbüchel A (2001) Preparative isolation of lipid 1398 inclusions from Rhodococcus opacus and Rhodococcus ruber and identification of granule- 1399 associated proteins. Arch Microbiol 177:20-28

Kalscheuer R, Stöveken T, Malkus U, Reichelt R, Golyshin PN, Sabirova JS, Ferrer M, Timmis 1401 KN, Steinbüchel A (2007) Analysis of storage lipid accumulation in Alcanivorax borkumensis: 1402 evidence for alternative triacylglycerol biosynthesis routes in bacteria. J Bacteriol 189:918-928 1403

Katavic V, Agrawal GK, Hajduch M, Harris SL, Thelen JJ (2006) Protein and lipid composition 1404 analysis of oil bodies from two Brassica napus cultivars. Proteomics 6:4586-4598 1405

Kellogg RB, Patton JS (1983) Lipid droplets, medium of energy exchange in the symbiotic 1406 anemone Condylactis gigantea: a model coral polyp. Mar Biol 75:137-149 1407

Kelly AA, Feussner I (2016) Oil is on the agenda: lipid turnover in higher plants. Biochim Biophys 1408 Acta 1861:1253-1268 1409

Kelly AA, Quettier A-L, Shaw E, Eastmond PJ (2011) Seed storage oil mobilization is important 1410 but not essential for germination or seedling establishment in Arabidopsis. Plant Physiol 1411 157:866-875 1412

Khandelia H, Duelund L, Pakkanen KI, Ipsen JH (2010) Triglyceride blisters in lipid bilayers: 1413 implications for lipid droplet biogenesis and the mobile lipid signal in cancer cell membranes. 1414 PLoS One 5:e12811

Kilaru A, Cao X, Dabbs PB, Sung H-J, Rahman MM, Thrower N, Zynda G, Podicheti R, Ibarra- 1416 Laclette E, Herrera-Estrella L, Mockaitis K, Ohlrogge JB (2015) Oil biosynthesis in a basal 1417 angiosperm: transcriptome analysis of Persea americana mesocarp. BMC Plant Biol 1418 15:203-203 1419

Kim M-J, Wainwright HC, Locketz M, Bekker L-G, Walther GB, Dittrich C, Visser A, Wang W, 1420 Hsu F-F, Wiehart U, Tsenova L, Kaplan G, Russell DG (2010) Caseation of human tuberculosis 1421 granulomas correlates with elevated host lipid metabolism. EMBO Mol Med 2:258-274 1422

Kimmel AR, Sztalryd C (2014) Perilipin 5, a lipid droplet protein adapted to mitochondrial energy 1423 utilization. Curr Opin Lipidol 25:110-117 1424

Kimmel AR, Sztalryd C (2016) The perilipins: major cytosolic lipid droplet-associated proteins and 1425 their roles in cellular lipid storage, mobilization, and systemic homeostasis. Annu Rev Nutr 1426 36:471-509

Kimmel AR, Brasaemle DL, Mcandrews-Hill M, Sztalryd C, Londos C (2010) Adoption of 1428 PERILIPIN as a unifying nomenclature for the mammalian PAT-family of intracellular lipid 1429 storage droplet proteins. J Lipid Res 51:468-471

Koch B, Schmidt C, Daum G (2014) Storage lipids of yeasts: a survey of nonpolar lipid metabolism 1431 in Saccharomyces cerevisiae, Pichia pastoris, and Yarrowia lipolytica. FEMS Microbiol Rev 1432 38:892-915 1433

Kong F, Romero IT, Warakanont J, Li-Beisson Y (2018) Lipid catabolism in microalgae. New 1434 Phytol 218:1340-1348 1435

Kory N, Farese RV, Walther TC (2016) Targeting fat: mechanisms of protein localization to lipid 1436 droplets. Trends Cell Biol 26:535-546 1437

Kreimer G (2009) The green algal eyespot apparatus: a primordial visual system and more? Curr 1438 Genet 55:19-43

Kretzschmar FK, Mengel LF, Müller A, Schmitt K, Blersch KF, Valerius O, Braus G, Ischebeck T 1440 (2018) PUX10 is a lipid droplet-localized scaffold protein that interacts with CDC48 and is 1441 involved in the degradation of lipid droplet proteins. Plant Cell 30:2137-2160 1442

Kuerschner L, Moessinger C, Thiele C (2007) Imaging of lipid biosynthesis: how a neutral lipid 1443 enters lipid droplets. Traffic 9:338-352 
1445 Kumar Y, Cocchiaro J, Valdivia RH (2006) The obligate intracellular pathogen Chlamydia 1446 trachomatis targets host lipid droplets. Curr Biol 16:1646-1651

1447 Kuntam S, Puskás LG, Ayaydin F (2015) Characterization of a new class of blue-fluorescent lipid 1448 droplet markers for live-cell imaging in plants. Plant Cell Rep 34:655-665

1449 Laibach N, Post J, Twyman RM, Gronover CS, Prüfer D (2015) The characteristics and potential 1450 applications of structural lipid droplet proteins in plants. J Biotechnol 201:15-27

1451 Leber R, Zinser E, Paltauf F, Daum G, Zellnig G (1994) Characterization of lipid particles of the 1452 yeast, Saccharomyces cerevisiae. Yeast 10:1421-1428

1453 Lee JH, Kong J, Jang JY, Han JS, Ji Y, Lee J, Kim JB (2014) Lipid droplet protein LID-1 mediates 1454 ATGL-1-dependent lipolysis during fasting in Caenorhabditis elegans. Mol Cell Biol 1455 34:4165-4176

1456 Lee YK, Sohn JH, Han JS, Park YJ, Jeon YG, Ji Y, Dalen KT, Sztalryd C, Kimmel AR, Kim JB 1457 (2018) Perilipin 3 deficiency stimulates thermogenic beige adipocytes through PPAR $\alpha$ activa1458 tion. Diabetes 67:791-804

1459 Lersten NR, Czlapinski AR, Curtis JD, Freckmann R, Horner HT (2006) Oil bodies in leaf 1460 mesophyll cells of angiosperms: overview and a selected survey. Am J Bot 93:1731-1739

1461 Leterrier M, Calleja P, Maréchal E (2015) Modified algae strain and method of triacylglycerol 1462 accumulation using said strain

1463 Li Z, Thiel K, Thul PJ, Beller M, Kühnlein RP, Welte MA (2012) Lipid droplets control the 1464 maternal histone supply of Drosophila embryos. Curr Biol 22:2104-2113

1465 Li X, Pan Y, Hu H (2018) Identification of the triacylglycerol lipase in the chloroplast envelope of 1466 the diatom Phaeodactylum tricornutum. Algal Res 33:440-447

1467 Lin L-J, Liao P-C, Yang H-H, Tzen JTC (2005) Determination and analyses of the N-termini of 1468 oil-body proteins, steroleosin, caleosin and oleosin. Plant Physiol Biochem 43:770-776

1469 Lin IP, Jiang P-L, Chen C-S, Tzen JTC (2012) A unique caleosin serving as the major integral 1470 protein in oil bodies isolated from Chlorella sp. cells cultured with limited nitrogen. Plant 1471 Physiol Biochem 61:80-87

1472 Lin P, Chen X, Moktan H, Arrese EL, Duan L, Wang L, Soulages JL, Zhou DH (2014) Membrane 1473 attachment and structure models of lipid storage droplet protein 1. Biochim Biophys Acta $1474 \quad 1838: 874-881$

1475 Liu H, Wang C, Chen F, Shen S (2015) Proteomic analysis of oil bodies in mature Jatropha curcas 1476 seeds with different lipid content. J Proteome 113:403-414

1477 Low KL, Shui G, Natter K, Yeo WK, Kohlwein SD, Dick T, Rao SPS, Wenk MR (2010) Lipid 1478 droplet-associated proteins are involved in the biosynthesis and hydrolysis of triacylglycerol in 1479 Mycobacterium bovis bacillus Calmette-Guérin. J Biol Chem 285:21662-21670

1480 Lu Y, Wang X, Balamurugan S, Yang W-D, Liu J-S, Dong H-P, Li H-Y (2017) Identification of a 1481 putative seipin ortholog involved in lipid accumulation in marine microalga Phaeodactylum 1482 tricornutum. J Appl Phycol 29:2821-2829

1483 Lundin C, Nordström R, Wagner K, Windpassinger C, Andersson H, Von Heijne G, Nilsson I 1484 (2006) Membrane topology of the human seipin protein. FEBS Lett 580:2281-2284

1485 Luo M, Fadeev EA, Groves JT (2005) Mycobactin-mediated iron acquisition within macrophages. 1486 Nat Chem Biol 1:149

1487 Lupette J, Maréchal E (2018) Phytoplankton glycerolipids: challenging but promising prospects 1488 from biomedicine to green chemistry and biofuels. Blue Biotechnology

1489 Lupette J, Lami R, Krasovec M, Grimsley N, Moreau H, Piganeau G, Sanchez-Ferandin S (2016) 1490 Marinobacter dominates the bacterial community of the Ostreococcus tauri phycosphere in 1491 culture. Front Microbiol 7:1414

1492 Lupette J, Jaussaud A, Seddiki K, Morabito C, Brugière S, Schaller H, Kuntz M, Putaux J-L, 1493 Jouneau P-H, Rébeillé F, Falconet D, Couté Y, Jouhet J, Tardif M, Salvaing J, Maréchal E 1494 (2019) The architecture of lipid droplets in the diatom Phaeodactylum tricornutum. Algal Res 1495 38:101415

1496 Madrigal-Matute J, Cuervo AM (2016) Regulation of liver metabolism by autophagy. Gastroen1497 terology 150:328-339 
Maeda Y, Sunaga Y, Yoshino T, Tanaka T (2014) Oleosome-associated protein of the oleaginous diatom Fistulifera solaris contains an endoplasmic reticulum-targeting signal sequence. Mar Drugs 12:3892-3903

Magré J, Delépine M, Khallouf E, Gedde-Dahl T Jr, Van Maldergem L, Sobel E, Papp J, Meier M, Mégarbané A, BWG, Lathrop M, Capeau J (2001) Identification of the gene altered in Berardinelli-Seip congenital lipodystrophy on chromosome 11q13. Nat Genet 28:365

Malchow D, Lüderitz O, Westphal O, Gerisch G, Riedeal V (1967) Polysaccharide in vegetativen und aggregationsreifen Amöben von Dictyostelium discoideum. Eur J Biochem 2:469-479

Maréchal E (2018) Primary endosymbiosis: emergence of the primary chloroplast and the chromatophore, two independent events. In: Maréchal E (ed) Plastids: methods and protocols. Springer, New York, pp 3-16

Marlowe IT, Brassell SC, Eglinton G, Green JC (1984a) Long chain unsaturated ketones and esters in living algae and marine sediments. Org Geochem 6:135-141 C39) alkenones in the Prymnesiophyceae. Distribution of alkenones and other lipids and their taxonomic significance. Br Phycol J 19:203-216

Mayer SV, Tesh RB, Vasilakis N (2017) The emergence of arthropod-borne viral diseases: a global prospective on dengue, chikungunya and zika fevers. Acta Trop 166:155-163 Graham CE, Bowman TA, Greenberg AS (2013) Perilipin-2-null mice are protected against diet-induced obesity, adipose inflammation, and fatty liver disease. J Lipid Res 54:1346-1359

Melo RCN, Weller PF (2016) Lipid droplets in leukocytes: organelles linked to inflammatory responses. Exp Cell Res 340:193-197

Menon D, Singh K, Pinto SM, Nandy A, Jaisinghani N, Kutum R, Dash D, Prasad TSK, Gandotra S (2019) Quantitative lipid droplet proteomics reveals mycobacterium tuberculosis induced alterations in macrophage response to infection. ACS Infect Dis 5:559-569 Fritz-Laylin LK, Maréchal-Drouard L, Marshall WF, Qu L-H, Nelson DR, Sanderfoot AA, Spalding MH, Kapitonov VV, Ren Q, Ferris P, Lindquist E, Shapiro H, Lucas SM, Grimwood J, Schmutz J, Cardol P, Cerutti H, Chanfreau G, Chen C-L, Cognat V, Croft MT, Dent R, Dutcher S, Fernández E, Ferris P, Fukuzawa H, González-Ballester D, González-Halphen D, Hallmann A, Hanikenne M, Hippler M, Inwood W, Jabbari K, Kalanon M, Kuras R, Lefebvre PA, Lemaire SD, Lobanov AV, Lohr M, Manuell A, Meier I, Mets L, Mittag M, Mittelmeier T, Moroney JV, Moseley J, Napoli C, Nedelcu AM, Niyogi K, Novoselov SV, Paulsen IT, Pazour G, Purton S, Ral J-P, Riaño-Pachón DM, Riekhof W, Rymarquis L, Schroda M, Stern D, Umen J, Willows R, Wilson N, Zimmer SL, Allmer J, Balk J, Bisova K, Chen C-J, Elias M, Gendler K, Hauser C, Lamb MR, Ledford H, Long JC, Minagawa J, Page MD, Pan J, Pootakham W, Roje S, Rose A, Stahlberg E, Terauchi AM, Yang P, Ball S, Bowler C, Dieckmann CL, Gladyshev VN, Green P, Jorgensen R, Mayfield S, Mueller-Roeber B, Rajamani S, Sayre RT et al (2007) The Chlamydomonas genome reveals the evolution of key animal and plant functions. Science 318:245-250

Meyer H, Bug M, Bremer S (2012) Emerging functions of the VCP/p97 AAA-ATPase in the 1539 ubiquitin system. Nat Cell Biol 14:117

Missaglia S, Valadares ER, Moro L, Faguntes EDT, Quintão Roque R, Giardina B, Tavian D (2014) 1541 Early onset of Chanarin-Dorfman syndrome with severe liver involvement in a patient with a 1542 complex rearrangement of ABHD5 promoter. BMC Med Genet 15:32-32

Miura S, Gan J-W, Brzostowski J, Parisi MJ, Schultz CJ, Londos C, Oliver B, Kimmel AR (2002) Functional conservation for lipid storage droplet association among perilipin, ADRP, and TIP47 (PAT)-related proteins in mammals, Drosophila, and Dictyostelium. J Biol Chem 277:32253-32257

Moellering ER, Benning C (2010) RNA interference silencing of a major lipid droplet protein 1548 affects lipid droplet size in Chlamydomonas reinhardtii. Eukaryot Cell 9:97-106 
1550 Moore H-PH, Silver RB, Mottillo EP, Bernlohr DA, Granneman JG (2005) Perilipin targets a novel 1551 pool of lipid droplets for lipolytic attack by hormone-sensitive lipase. J Biol Chem 1552 280:43109-43120

1553 Morabito C, Bournaud C, Maës C, Schuler M, Aiese Cigliano R, Dellero Y, Maréchal E, Amato A, 1554 Rébeillé F (2019) The lipid metabolism in thraustochytrids. Prog Lipid Res 76:101007

1555 Możejko-Ciesielska J, Kiewisz R (2016) Bacterial polyhydroxyalkanoates: still fabulous? 1556 Microbiol Res 192:271-282

1557 Müller AO, Blersch KF, Gippert AL, Ischebeck T (2016) Tobacco pollen tubes - a fast and easy 1558 tool for studying lipid droplet association of plant proteins. Plant J 89:1055-1064

1559 Murphy DJ (2012) The dynamic roles of intracellular lipid droplets: from archaea to mammals. 1560 Protoplasma 249:541-585

$1561 \mathrm{Na} \mathrm{H}$, Zhang P, Chen Y, Zhu X, Liu Y, Liu Y, Xie K, Xu N, Yang F, Yu Y, Cichello S, Mak HY, 1562 Wang MC, Zhang H, Liu P (2015) Identification of lipid droplet structure-like/resident proteins 1563 in Caenorhabditis elegans. Biochim Biophys Acta 1853:2481-2491

1564 Najt CP, Lwande JS, Mcintosh AL, Senthivinayagam S, Gupta S, Kuhn LA, Atshaves BP (2014) 1565 Structural and functional assessment of perilipin 2 lipid binding domain(s). Biochemistry 1566 53:7051-7066

1567 Nchoutmboube JA, Viktorova EG, Scott AJ, Ford LA, Pei Z, Watkins PA, Ernst RK, Belov GA 1568 (2013) Increased long chain acyl-Coa synthetase activity and fatty acid import is linked to 1569 membrane synthesis for development of picornavirus replication organelles. PLoS Pathog 9: 1570 e1003401

1571 Nguyen HM, Baudet M, Cuiné S, Adriano J-M, Barthe D, Billon E, Bruley C, Beisson F, Peltier G, 1572 Ferro M, Li-Beisson Y (2011) Proteomic profiling of oil bodies isolated from the unicellular 1573 green microalga Chlamydomonas reinhardtii: with focus on proteins involved in lipid metab1574 olism. Proteomics 11:4266-4273

1575 Nishino N, Tamori Y, Tateya S, Kawaguchi T, Shibakusa T, Mizunoya W, Inoue K, Kitazawa R, 1576 Kitazawa S, Matsuki Y, Hiramatsu R, Masubuchi S, Omachi A, Kimura K, Saito M, Amo T, 1577 Ohta S, Yamaguchi T, Osumi T, Cheng J, Fujimoto T, Nakao H, Nakao K, Aiba A, Okamura H, 1578 Fushiki T, Kasuga M (2008) FSP27 contributes to efficient energy storage in murine white 1579 adipocytes by promoting the formation of unilocular lipid droplets. J Clin Invest 118:2808-2821 1580 Nojima D, Yoshino T, Maeda Y, Tanaka M, Nemoto M, Tanaka T (2013) Proteomics analysis of oil 1581 body-associated proteins in the oleaginous diatom. J Proteome Res 12:5293-5301

1582 Noothalapati Venkata HN, Shigeto S (2012) Stable isotope-labeled Raman imaging reveals 1583 dynamic proteome localization to lipid droplets in single fission yeast cells. Chem Biol $1584 \quad 19: 1373-1380$

1585 Okuda-Shimizu Y, Hendershot LM (2007) Characterization of an ERAD pathway for 1586 non-glycosylated BiP substrates which requires Herp. Mol Cell 28:544-554

1587 Oliva J, French SW, Li J, Bardag-Gorce F (2012) Proteasome inhibitor treatment reduced fatty acid, 1588 triacylglycerol and cholesterol synthesis. Exp Mol Pathol 93:26-34

1589 Olzmann JA, Kopito RR, Christianson JC (2013a) The mammalian endoplasmic reticulum1590 associated degradation system. Cold Spring Harb Perspect Biol:5, a013185. https://doi.org/10. 1591 1101/cshperspect.a013185

1592 Olzmann JA, Richter CM, Kopito RR (2013b) Spatial regulation of UBXD8 and p97/VCP controls 1593 ATGL-mediated lipid droplet turnover. Proc Natl Acad Sci USA 110:1345-1350

1594 Onal G, Kutlu O, Gozuacik D, Dokmeci Emre S (2017) Lipid droplets in health and disease. Lipids 1595 Health Dis 16:128

1596 Paar M, Jüngst C, Steiner NA, Magnes C, Sinner F, Kolb D, Lass A, Zimmermann R, Zumbusch A, 1597 Kohlwein SD, Wolinski H (2012) Remodeling of lipid droplets during lipolysis and growth in 1598 adipocytes. J Biol Chem 287:11164-11173

1599 Park S, Gidda SK, James CN, Horn PJ, Khuu N, Seay DC, Keereetaweep J, Chapman KD, Mullen 1600 RT, Dyer JM (2013) The $\alpha / \beta$ hydrolase CGI-58 and peroxisomal transport protein PXA1 1601 coregulate lipid homeostasis and signaling in Arabidopsis. Plant Cell 25:1726-1739 
11 The Puzzling Conservation and Diversification of Lipid Droplets from Bacteria...

Park S, Keereetaweep J, James CN, Gidda SK, Chapman KD, Mullen RT, Dyer JM (2014) CGI-58, 1602 a key regulator of lipid homeostasis and signaling in plants, also regulates polyamine metabo- 1603 lism. Plant Signal Behav 9:e27723

Pasaribu B, Lin IP, Chen C-S, Lu C-Y, Jiang P-L (2014a) Nutrient limitation in Auxenochlorella 1605 protothecoides induces qualitative changes of fatty acid and expression of caleosin as a 1606 membrane protein associated with oil bodies. Biotechnol Lett 36:175-180 1607

Pasaribu B, Lin IP, Tzen JTC, Jauh G-Y, Fan T-Y, Ju Y-M, Cheng J-O, Chen C-S, Jiang P-L 1608 (2014b) SLDP: a novel protein related to caleosin is associated with the endosymbiotic 1609 symbiodinium lipid droplets from Euphyllia glabrescens. Mar Biotechnol 16:560-571 1610

Peled E, Leu S, Zarka A, Weiss M, Pick U, Khozin-Goldberg I, Boussiba S (2011) Isolation of a 1611 novel oil globule protein from the green alga Haematococcus pluvialis (Chlorophyceae). Lipids 1612 46:851-861

Peng S-E, Chen W-NU, Chen H-K, Lu C-Y, Mayfield AB, Fang L-S, Chen C-S (2011) Lipid bodies in coral-dinoflagellate endosymbiosis: proteomic and ultrastructural studies. Proteomics 11:3540-3555

1613

1614 1615 1616

Pericleous M, Kelly C, Wang T, Livingstone C, Ala A (2017) Wolman's disease and cholesteryl 1617 ester storage disorder: the phenotypic spectrum of lysosomal acid lipase deficiency. Lancet 1618 Gastroenterol Hepatol 2:670-679

Petroutsos D, Amiar S, Abida H, Dolch L-J, Bastien O, Rébeillé F, Jouhet J, Falconet D, Block MA, 1620 Mcfadden GI, Bowler C, Botté C, Maréchal E (2014) Evolution of galactoglycerolipid biosyn- 1621 thetic pathways - from cyanobacteria to primary plastids and from primary to secondary 1622 plastids. Prog Lipid Res 54:68-85 1623

Pol A, Gross SP, Parton RG (2014) Biogenesis of the multifunctional lipid droplet: lipids, proteins, 1624 and sites. J Cell Biol 204:635-646 1625

Popluechai S, Froissard M, Jolivet P, Breviario D, Gatehouse AMR, O'donnell AG, Chardot T, 1626 Kohli A (2011) Jatropha curcas oil body proteome and oleosins: L-form JcOle3 as a potential 1627 phylogenetic marker. Plant Physiol Biochem 49:352-356 1628

Pötter M, Steinbüchel A (2006) Biogenesis and structure of polyhydroxyalkanoate granules. In: 1629 Shively JM (ed) Inclusions in prokaryotes. Springer, Berlin, pp 109-136 1630

Poulsen LLC, Siersbæk M, Mandrup S (2012) PPARs: fatty acid sensors controlling metabolism. 1631 Semin Cell Dev Biol 23:631-639 1632

Qu R, Wang SM, Lin YH, Vance VB, Huang AH (1986) Characteristics and biosynthesis of 1633 membrane proteins of lipid bodies in the scutella of maize (Zea mays L.). Biochem J 235:57-65 1634

Quettier A-L, Eastmond PJ (2009) Storage oil hydrolysis during early seedling growth. Plant 1635 Physiol Biochem 47:485-490 1636

Rapoport TA (2007) Protein translocation across the eukaryotic endoplasmic reticulum and bacte- 1637 rial plasma membranes. Nature 450:663 1638

Reinecke F, Steinbüchel A (2009) Ralstonia eutropha strain H16 as model organism for PHA 1639 metabolism and for biotechnological production of technically interesting biopolymers. J Mol 1640 Microbiol Biotechnol 16:91-108 1641

Roingeard P, Melo RCN (2017) Lipid droplet hijacking by intracellular pathogens. Cell Microbiol 1642 19:e12688 1643

Ruggiano A, Mora G, Buxó L, Carvalho P (2016) Spatial control of lipid droplet proteins by the 1644 ERAD ubiquitin ligase Doa10. EMBO J 35:1644-1655 1645

Rumin J, Bonnefond H, Saint-Jean B, Rouxel C, Sciandra A, Bernard O, Cadoret J-P, Bougaran G 1646 (2015) The use of fluorescent Nile red and BODIPY for lipid measurement in microalgae. 1647 Biotechnol Biofuels 8:42 1648

Rydel TJ, Williams JM, Krieger E, Moshiri F, Stallings WC, Brown SM, Pershing JC, Purcell JP, 1649 Alibhai MF (2003) The crystal structure, mutagenesis, and activity studies reveal that patatin is a 1650 lipid acyl hydrolase with a Ser-Asp catalytic dyad. Biochemistry 42:6696-6708 1651

Sahu-Osen A, Montero-Moran G, Schittmayer M, Fritz K, Dinh A, Chang Y-F, Mcmahon D, 1652 Boeszoermenyi A, Cornaciu I, Russell D, Oberer M, Carman GM, Birner-Gruenberger R, 1653 
1654 Brasaemle DL (2015) CGI-58/ABHD5 is phosphorylated on Ser239 by protein kinase a: control 1655 of subcellular localization. J Lipid Res 56:109-121

1656 Saka HA, Thompson JW, Chen Y-S, Dubois LG, Haas JT, Moseley A, Valdivia RH (2015) 1657 Chlamydia trachomatis infection leads to defined alterations to the lipid droplet proteome in 1658 epithelial cells. PLoS One 10:e0124630

1659 Salo VT, Belevich I, Li S, Karhinen L, Vihinen H, Vigouroux C, Magré J, Thiele C, Hölttä-Vuori M, 1660 Jokitalo E, Ikonen E (2016) Seipin regulates ER-lipid droplet contacts and cargo delivery. 1661 EMBO J 35:2699-2716

1662 Sando T, Hayashi T, Takeda T, Akiyama Y, Nakazawa Y, Fukusaki E, Kobayashi A (2009) 1663 Histochemical study of detailed laticifer structure and rubber biosynthesis-related protein 1664 localization in Hevea brasiliensis using spectral confocal laser scanning microscopy. Planta 1665 230:215-225

1666 Sardet C (2013) Plancton - Aux origines du vivant

1667 Schweiger M, Paar M, Eder C, Brandis J, Moser E, Gorkiewicz G, Grond S, Radner FPW, Cerk I, 1668 Cornaciu I, Oberer M, Kersten S, Zechner R, Zimmermann R, Lass A (2012) G0/G1 switch 1669 gene-2 regulates human adipocyte lipolysis by affecting activity and localization of adipose 1670 triglyceride lipase. J Lipid Res 53:2307-2317

1671 Sharma B, Joshi D, Yadav PK, Gupta AK, Bhatt TK (2016) Role of ubiquitin-mediated degradation 1672 system in plant biology. Front Plant Sci 7:806

1673 Shen P, Zhao Q, Yao C, Wu S, Meng Y, Zhang L, Xue S (2016) Differential proteome analysis and 1674 identification of lipid droplet associated proteins in the marine microalgae Isochrysis 1675 zhangjiangensis (Haptophyta). In: The 4th Asia-Oceania algae innovation summit. Wuhan 1676 Shi Q (2019) Expression profiling of genes coding for abundant proteins in the alkenone body of 1677 marine haptophyte alga Tisochrysis lutea. BMC Microbiol 19:56-56

1678 Shi X, Li J, Zou X, Greggain J, Rødkær SV, Færgeman NJ, Liang B, Watts JL (2013) Regulation of 1679 lipid droplet size and phospholipid composition by stearoyl-CoA desaturase. J Lipid Res $1680 \quad 54: 2504-2514$

1681 Shi Q, Araie H, Bakku RK, Fukao Y, Rakwal R, Suzuki I, Shiraiwa Y (2015) Proteomic analysis of 1682 lipid body from the alkenone-producing marine haptophyte alga Tisochrysis lutea. Proteomics $1683 \quad 15: 4145-4158$

1684 Shimada TL, Hara-Nishimura I (2015) Leaf oil bodies are subcellular factories producing antifungal 1685 oxylipins. Curr Opin Plant Biol 25:145-150

1686 Shimada TL, Takano Y, Shimada T, Fujiwara M, Fukao Y, Mori M, Okazaki Y, Saito K, Sasaki R, 1687 Aoki K, Hara-Nishimura I (2014) Leaf oil body functions as a subcellular factory for the 1688 production of a Phytoalexin in Arabidopsis. Plant Physiol 164:105-118

1689 Shimada TL, Takano Y, Hara-Nishimura I (2015) Oil body-mediated defense against fungi: from 1690 tissues to ecology. Plant Signal Behav 10:e989036

1691 Siegler H, Valerius O, Ischebeck T, Popko J, Tourasse NJ, Vallon O, Khozin-Goldberg I, Braus 1692 GH, Feussner I (2017) Analysis of the lipid body proteome of the oleaginous alga Lobosphaera 1693 incisa. BMC Plant Biol 17:98

1694 Song P, Li L, Liu J (2013) Proteomic analysis in nitrogen-deprived Isochrysis galbana during lipid 1695 accumulation. PLoS One 8:e82188-e82188

1696 Soni KG, Mardones GA, Sougrat R, Smirnova E, Jackson CL, Bonifacino JS (2009) Coatomer1697 dependent protein delivery to lipid droplets. J Cell Sci 122:1834

1698 Soulages JL, Firdaus SJ, Hartson S, Chen X, Howard AD, Arrese EL (2012) Developmental 1699 changes in the protein composition of Manduca sexta lipid droplets. Insect Biochem Mol Biol $1700 \quad 42: 305-320$

1701 Souza SC, De Vargas LM, Yamamoto MT, Lien P, Franciosa MD, Moss LG, Greenberg AS (1998) 1702 Overexpression of Perilipin A and B blocks the ability of tumor necrosis factor $\alpha$ to increase 1703 lipolysis in 3T3-L1 adipocytes. J Biol Chem 273:24665-24669

1704 Stevenson J, Huang EY, Olzmann JA (2016) Endoplasmic reticulum-associated degradation and 1705 lipid homeostasis. Annu Rev Nutr 36:511-542 
11 The Puzzling Conservation and Diversification of Lipid Droplets from Bacteria...

Stone SJ, Levin MC, Zhou P, Han J, Walther TC, Farese RV (2009) The endoplasmic reticulum 1706 enzyme DGAT2 is found in mitochondria-associated membranes and has a mitochondrial 1707 targeting signal that promotes its association with mitochondria. J Biol Chem 284:5352-5361 1708

Subramanian V, Rothenberg A, Gomez C, Cohen AW, Garcia A, Bhattacharyya S, Shapiro L, 1709 Dolios G, Wang R, Lisanti MP, Brasaemle DL (2004) Perilipin a mediates the reversible 1710 binding of CGI-58 to lipid droplets in 3T3-L1 adipocytes. J Biol Chem 279:42062-42071 1711

Sun Z, Gong J, Wu H, Xu W, Wu L, Xu D, Gao J, Wu J-W, Yang H, Yang M, Li P (2013) 1712 Perilipin1 promotes unilocular lipid droplet formation through the activation of Fsp27 in 1713 adipocytes. Nat Commun 4:1594

1714

Suzuki M, Otsuka T, Ohsaki Y, Cheng J, Taniguchi T, Hashimoto H, Taniguchi H, Fujimoto T 1715 (2012) Derlin-1 and UBXD8 are engaged in dislocation and degradation of lipidated ApoB- 1716 100 at lipid droplets. Mol Biol Cell 23:800-810

Sznajder A, Jendrossek D (2014) To be or not to be a poly(3-hydroxybutyrate) (PHB) 1718 depolymerase: PhaZd1 (PhaZ6) and PhaZd2 (PhaZ7) of Ralstonia eutropha, highly active 1719 PHB depolymerases with no detectable role in mobilization of accumulated PHB. Appl Environ 1720 Microbiol 80:4936-4946

Tansey JT, Sztalryd C, Gruia-Gray J, Roush DL, Zee JV, Gavrilova O, Reitman ML, Deng CX, 1722 Li C, Kimmel AR, Londos C (2001) Perilipin ablation results in a lean mouse with aberrant 1723 adipocyte lipolysis, enhanced leptin production, and resistance to diet-induced obesity. Proc 1724 Natl Acad Sci 98:6494

1725

Tauchi-Sato K, Ozeki S, Houjou T, Taguchi R, Fujimoto T (2002) The surface of lipid droplets is a 1726 phospholipid monolayer with a unique fatty acid composition. J Biol Chem 277:44507-44512 1727

Taurino M, Costantini S, De Domenico S, Stefanelli F, Ruano G, Delgadillo MO, Sanchez-Serrano 1728 JJ, Sanmartín M, Santino A, Rojo E (2017) SEIPIN proteins mediate lipid droplet biogenesis to 1729 promote pollen transmission and reduce seed dormancy. Plant Physiol 176:1531-1546 1730

Theodoulou FL, Job K, Slocombe SP, Footitt S, Holdsworth M, Baker A, Larson TR, Graham IA 1731 (2005) Jasmonic acid levels are reduced in COMATOSE ATP-binding cassette transporter 1732 mutants. Implications for transport of jasmonate precursors into peroxisomes. Plant Physiol 1733 137:835-840

Thiam AR, Forêt L (2016) The physics of lipid droplet nucleation, growth and budding. Biochim 1735 Biophys Acta 1861:715-722

Thiam AR, Antonny B, Wang J, Delacotte J, Wilfling F, Walther TC, Beck R, Rothman JE, Pincet F 1737 (2013a) COPI buds 60-nm lipid droplets from reconstituted water-phospholipid- 1738 triacylglyceride interfaces, suggesting a tension clamp function. Proc Natl Acad Sci USA 1739 110:13244-13249

Thiam AR, Farese RV Jr, Walther TC (2013b) The biophysics and cell biology of lipid droplets. Nat 1741 Rev Mol Cell Biol 14:775

Thul PJ, Tschapalda K, Kolkhof P, Thiam AR, Oberer M, Beller M (2017) Targeting of the 1743 Drosophila protein CG2254/Ldsdh1 to a subset of lipid droplets. J Cell Sci 130:3141 1744

Tnani H, López I, Jouenne T, Vicient CM (2011) Protein composition analysis of oil bodies from 1745 maize embryos during germination. J Plant Physiol 168:510-513 1746

Trentacoste EM, Shrestha RP, Smith SR, Glé C, Hartmann AC, Hildebrand M, Gerwick WH (2013) 1747 Metabolic engineering of lipid catabolism increases microalgal lipid accumulation without 1748 compromising growth. Proc Natl Acad Sci USA 110:19748-19753 1749

Uchino K, Saito T, Jendrossek D (2008) Poly(3-hydroxybutyrate) (PHB) depolymerase PhaZa1 is 1750 involved in mobilization of accumulated PHB in Ralstonia eutropha H16. Appl Environ 1751 Microbiol 74:1058-1063

Van Wijk KJ, Kessler F (2017) Plastoglobuli: plastid microcompartments with integrated functions 1753 in metabolism, plastid developmental transitions, and environmental adaptation. Annu Rev 1754 Plant Biol 68:253-289

Vance VB, Huang AH (1987) The major protein from lipid bodies of maize. Characterization and 1756 structure based on cDNA cloning. J Biol Chem 262:11275-11279 
1758 Varela GM, Antwi DA, Dhir R, Yin X, Singhal NS, Graham MJ, Crooke RM, Ahima RS (2008) 1759 Inhibition of ADRP prevents diet-induced insulin resistance. Am J Physiol Gastrointest Liver 1760 Physiol 295:G621-G628

1761 Vermachova M, Purkrtova Z, Santrucek J, Jolivet P, Chardot T, Kodicek M (2011) New protein 1762 isoforms identified within Arabidopsis thaliana seed oil bodies combining chymotrypsin/ 1763 trypsin digestion and peptide fragmentation analysis. Proteomics 11:3430-3434

1764 Vieler A, Wu G, Tsai C-H, Bullard B, Cornish AJ, Harvey C, Reca I-B, Thornburg C, 1765 Achawanantakun R, Buehl CJ, Campbell MS, Cavalier D, Childs KL, Clark TJ, 1766 Deshpande R, Erickson E, Armenia Ferguson A, Handee W, Kong Q, Li X, Liu B, 1767 Lundback S, Peng C, Roston RL, Sanjaya, Simpson JP, Terbush A, Warakanont J, Zäuner S, 1768 Farre EM, Hegg EL, Jiang N, Kuo M-H, Lu Y, Niyogi KK, Ohlrogge J, Osteryoung KW, 1769 Shachar-Hill Y, Sears BB, Sun Y, Takahashi H, Yandell M, Shiu S-H, Benning C (2012) 1770 Genome, functional gene annotation, and nuclear transformation of the heterokont oleaginous 1771 alga Nannochloropsis oceanica CCMP1779. PLoS Genet 8:e1003064

1772 Viswanadha S, Londos C (2008) Determination of lipolysis in isolated primary adipocytes. In: 1773 Yang K (ed) Adipose tissue protocols. Humana Press, Totowa, pp 299-306

1774 Vrablik TL, Petyuk VA, Larson EM, Smith RD, Watts JL (2015) Lipidomic and proteomic analysis 1775 of C. elegans lipid droplets and identification of ACS-4 as a lipid droplet-associated protein. 1776 Biochim Biophys Acta 1851:1337-1345

1777 Wältermann M, Steinbüchel A (2005) Neutral lipid bodies in prokaryotes: recent insights into 1778 structure, formation, and relationship to eukaryotic lipid depots. J Bacteriol 187:3607-3619

1779 Walther TC, Chung J, Farese RV (2017) Lipid droplet biogenesis. Annu Rev Cell Dev Biol $1780 \quad 33: 491-510$

1781 Wang H, Becuwe M, Housden BE, Chitraju C, Porras AJ, Graham MM, Liu XN, Thiam AR, 1782 Savage DB, Agarwal AK, Garg A, Olarte M-J, Lin Q, Fröhlich F, Hannibal-Bach HK, 1783 Upadhyayula S, Perrimon N, Kirchhausen T, Ejsing CS, Walther TC, Farese RV (2016) Seipin 1784 is required for converting nascent to mature lipid droplets. elife 5:e16582

1785 Watanabe T, Sakiyama R, Iimi Y, Sekine S, Abe E, Nomura KH, Nomura K, Ishibashi Y, Okino N, 1786 Hayashi M, Ito M (2017) Regulation of TG accumulation and lipid droplet morphology by the 1787 novel TLDP1 in Aurantiochytrium limacinum F26-b. J Lipid Res 58:2334-2347

1788 Wilfling F, Wang H, Haas JT, Krahmer N, Gould TJ, Uchida A, Cheng J-X, Graham M, 1789 Christiano R, Fröhlich F, Liu X, Buhman KK, Coleman RA, Bewersdorf J, Farese RV, Walther 1790 TC (2013) Triacylglycerol synthesis enzymes mediate lipid droplet growth by relocalizing from 1791 the ER to lipid droplets. Dev Cell 24:384-399

1792 Wilfling F, Haas JT, Walther TC, Farese RV (2014) Lipid droplet biogenesis. Curr Opin Cell Biol $1793 \quad 29: 39-45$

1794 Wolman M, Sterk VV, Gatt S, Frenkel M (1961) Primary familial xanthomatosis with involvement 1795 and calcification of the adrenals. Report of two more cases in siblings of a previously described 1796 infant. Pediatrics 25:742-757

1797 Xie M, Roy R (2015) The causative gene in Chanarian Dorfman syndrome regulates lipid droplet 1798 homeostasis in C. elegans. PLoS Genet 11:e1005284-e1005284

1799 Yang H-J, Hsu C-L, Yang J-Y, Yang WY (2012) Monodansylpentane as a blue-fluorescent lipid1800 droplet marker for multi-color live-cell imaging. PLoS One 7:e32693

1801 Yermanos DM (1975) Composition of jojoba seed during development. J Am Oil Chem Soc $1802 \quad 52: 115-117$

1803 Yoneda K, Yoshida M, Suzuki I, Watanabe MM (2016) Identification of a major lipid droplet 1804 protein in a marine diatom Phaeodactylum tricornutum. Plant Cell Physiol 57:397-406

1805 Yoneda K, Yoshida M, Suzuki I, Watanabe MM (2018) Homologous expression of lipid droplet 1806 protein-enhanced neutral lipid accumulation in the marine diatom Phaeodactylum tricornutum. 1807 J Appl Phycol 30:2793-2802

1808 Youssef A, Laizet YH, Block MA, Maréchal E, Alcaraz J-P, Larson TR, Pontier D, Gaffé J, Kuntz 1809 M (2010) Plant lipid-associated fibrillin proteins condition jasmonate production under photo1810 synthetic stress. Plant J 61:436-445 
11 The Puzzling Conservation and Diversification of Lipid Droplets from Bacteria...

Yu J, Zhang S, Cui L, Wang W, Na H, Zhu X, Li L, Xu G, Yang F, Christian M, Liu P (2015) Lipid 1811 droplet remodeling and interaction with mitochondria in mouse brown adipose tissue during 1812 cold treatment. Biochim Biophys Acta 1853:918-928 1813

Yu Y, Li T, Wu N, Jiang L, Ji X, Huang H (2017) The role of lipid droplets in Mortierella alpina 1814 aging revealed by integrative subcellular and whole-cell proteome analysis. Sci Rep 7:43896 1815

Zhang C, Liu P (2017) The lipid droplet: a conserved cellular organelle. Protein Cell 8:796-800 1816

Zhang P, Na H, Liu Z, Zhang S, Xue P, Chen Y, Pu J, Peng G, Huang X, Yang F, Xie Z, Xu T, 1817 Xu P, Ou G, Zhang SO, Liu P (2012) Proteomic study and marker protein identification of 1818 Caenorhabditis elegans lipid droplets. Mol Cell Proteomics 11:317-328 1819

Zhang J, Zhang Z, Chukkapalli V, Nchoutmboube JA, Li J, Randall G, Belov GA, Wang X (2016) 1820 Positive-strand RNA viruses stimulate host phosphatidylcholine synthesis at viral replication 1821 sites. Proc Natl Acad Sci USA 113:E1064-E1073

Zhang C, Yang L, Ding Y, Wang Y, Lan L, Ma Q, Chi X, Wei P, Zhao Y, Steinbüchel A, Zhang H, 1823 Liu P (2017) Bacterial lipid droplets bind to DNA via an intermediary protein that enhances 1824 survival under stress. Nat Commun 8:15979 1825

Zhu Z, Ding Y, Gong Z, Yang L, Zhang S, Zhang C, Lin X, Shen H, Zou H, Xie Z, Yang F, Zhao X, 1826 Liu P, Zhao ZK (2015) Dynamics of the lipid droplet proteome of the oleaginous yeast 1827 Rhodosporidium toruloides. Eukaryot Cell 14:252-264 1828

Zimmermann R, Strauss JG, Haemmerle G, Schoiswohl G, Birner-Gruenberger R, Riederer M, 1829 Lass A, Neuberger G, Eisenhaber F, Hermetter A, Zechner R (2004) Fat mobilization in adipose 1830 tissue is promoted by adipose triglyceride lipase. Science 306:1383-1386 


\section{Author Queries}

Chapter No.: 11 483283_1_En

\begin{tabular}{|l|l|l|}
\hline Query Refs. & Details Required & Author's response \\
\hline AU1 & $\begin{array}{l}\text { Please check and confirm if the } \\
\text { affiliations are presented correctly. }\end{array}$ & \\
\hline AU2 & $\begin{array}{l}\text { Please check the hierarchy } \\
\text { of the section headings and confirm } \\
\text { if correct. }\end{array}$ & \\
\hline
\end{tabular}




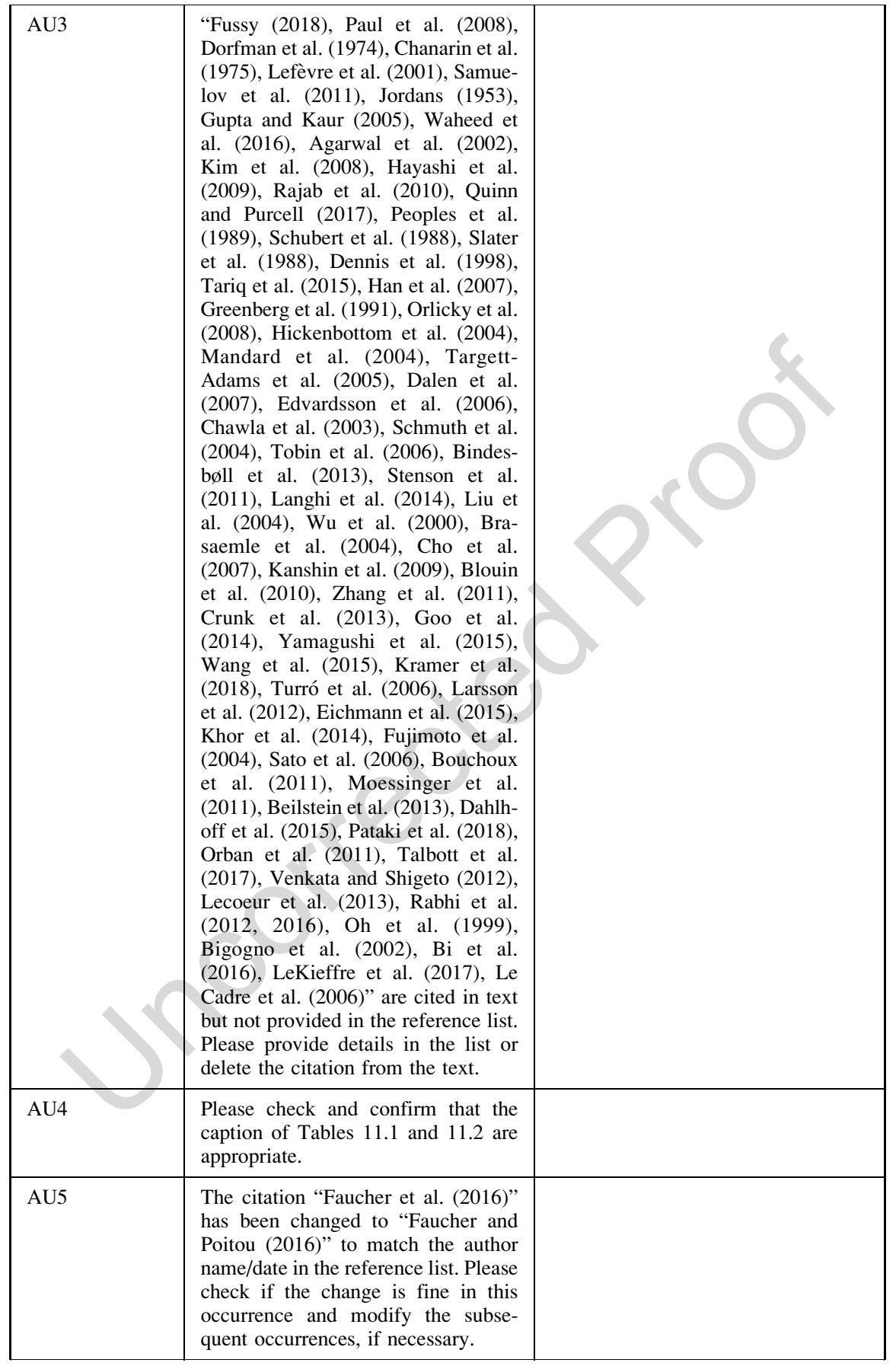




\begin{tabular}{|l|l|l|}
\hline AU6 & $\begin{array}{l}\text { The citation "Madrigal-Matute et al. } \\
\text { (2016)" has been changed to "Ma- } \\
\text { drigal-Matute and Cuervo (2016)" to } \\
\text { match the author name/date in the } \\
\text { reference list. Please check if the } \\
\text { change is fine in this occurrence and } \\
\text { modify the subsequent occurrences, } \\
\text { if necessary. }\end{array}$ & $\begin{array}{l}\text { Please check and confirm that the } \\
\text { layout of the Table 11.2 is set as } \\
\text { correct. }\end{array}$ \\
\hline AU7 & $\begin{array}{l}\text { The citation "Melo et al. (2016)" has } \\
\text { been changed to "Melo and Weller } \\
\text { (2016)" to match the author name/ } \\
\text { date in the reference list. Please } \\
\text { check if the change is fine in this } \\
\text { occurrence and modify the subse- } \\
\text { quent occurrences, if necessary. }\end{array}$ & \\
\hline AU9 & $\begin{array}{l}\text { The citation "Ding et al. (2012)" has } \\
\text { been changed to "Ding et al. (2012a, } \\
\text { b)" to match the author name/date in } \\
\text { the reference list. Please check if the } \\
\text { change is fine in this occurrence and } \\
\text { modify the subsequent occurrences, } \\
\text { if necessary. }\end{array}$ & \\
\hline AU11 & $\begin{array}{l}\text { The citation "Kimmel et al. (2016)" } \\
\text { has been changed to "Kimmel and } \\
\text { Sztalryd (2016)" to match the author } \\
\text { name/date in the reference list. Please } \\
\text { check if the change is fine in this } \\
\text { occurrence and modify the subse- } \\
\text { quent occurrences, if necessary. }\end{array}$ & $\begin{array}{l}\text { Please check and provide appropriate } \\
\text { name and date reference citation } \\
\text { instead of numbered citations [19, } \\
\text { 229, 230] which is cited here. }\end{array}$ \\
\hline AU10 & $\begin{array}{l}\text { Please update the details for the } \\
\text { references "Leterrier et al. (2015), } \\
\text { Sardet (2013)", if applicable. }\end{array}$ & \\
\hline
\end{tabular}

